\section{مؤشرات تقرير المصير بِ برامج التربية الخاصة يِ الأردن \\ إيمان خليف علي الزيون * وجميل محمود الصمادي \\ الجامعة الاردنية، عمان، الأردن}

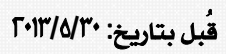

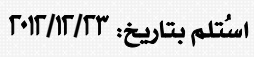

هدفت هذه الدراسة إلى التعرف إلى مستوى التزام برامج التربية الخاصة ِِّ الأردن بالمؤشرات النوعية لتقرير المصير. تكوّتت عينة الدراسة من

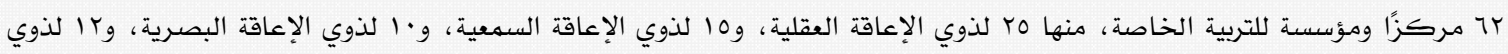

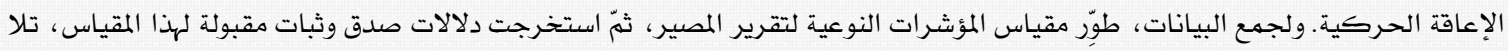

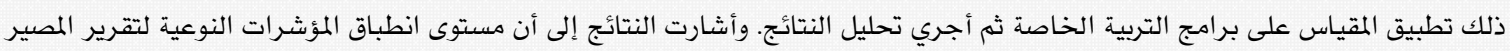

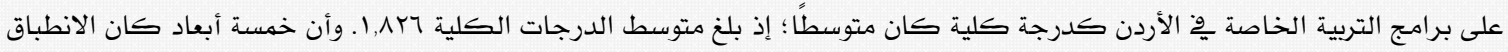

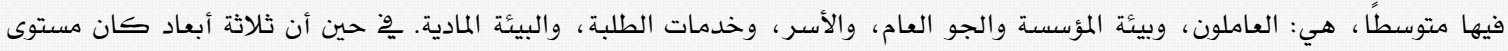

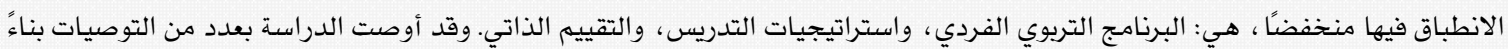
على نتائج الدراسة. كلمات مفتاحية: تقرير المصير، الأشخاص ذوي الإعاقة ، برامج التربية الخاصة، الأردن.

\title{
Q uality Indicators of Self- Determination of Special Education Programs in Jordan
}

Eman K. AL-Zboon*, Jamil M. Smadi Jordan University, A mman, Jordan

This study aimed to identify the level of commitment of special education programs in Jordan by means of qualitative indicators for self-determination. The sample consisted of 62 special education centers and institutions: 25 for intellectual disability, 15 for hearing disability, 10 for visual disability, and 12 for physical disability. To achieve the aim of the study, a self-determination scale of qualitative indicators was developed and an acceptable level of validity and reliability was derived before being applied to special education programs. The results revealed that special education programs that employ quality indicators of selfdetermination are at medium level. Also, at the medium level were the domains of staff, institution atmosphere, family, students' services, and physical environment. However, in the domains of individual educational programs, instructional strategies and self-evaluation, the level was low. The study proposed a set of recommendations based on the findings of the study.

Keyw ords: self-determination, individuals with special needs, special education programs, Jordan

*emanzboon@yahoo.com 


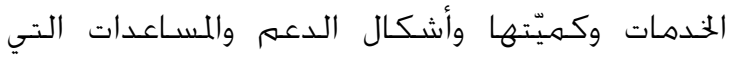

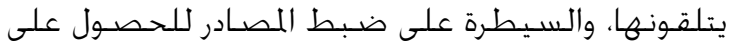

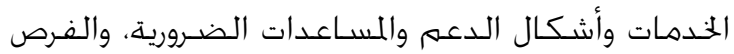

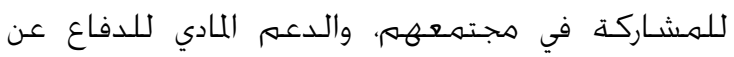

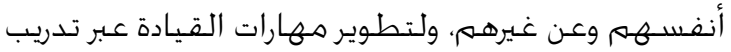

مهارات الدفاع عن الذات (Wehmeyer et al., 2007). إضـافة إلى ذلك، فإن هنالك اجزاهًا لتعريف تقرير المصير

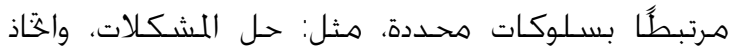

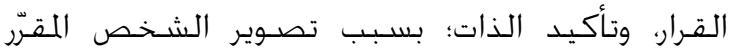

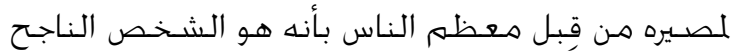

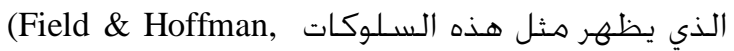

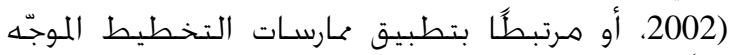

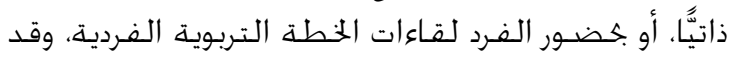

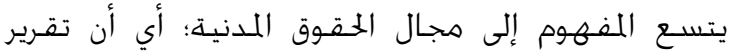

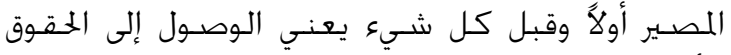

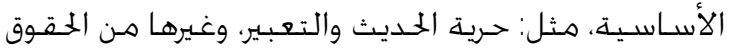

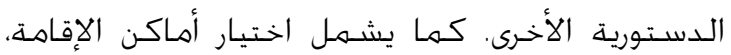

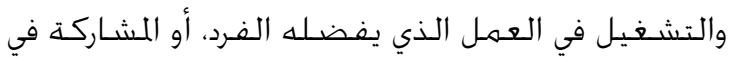

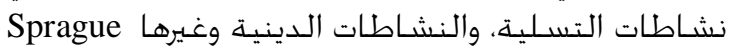

.(\& Hayes, 2000)

كما وصف تقرير المصير بوصفه هـدفًا وبناءً تربويًّا. وهذا

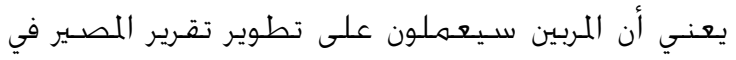

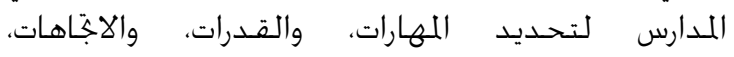
والمعتقدات التي تقود إلى تقرير المسير، ولتصـيم التحاتيم التدريس لتحقيق هذا النتاج (Wehmeyer et al., 2007).

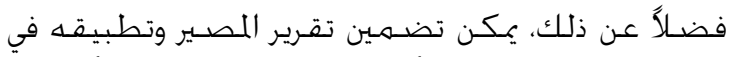

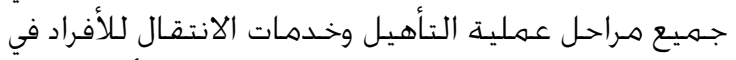

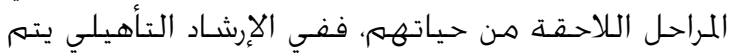

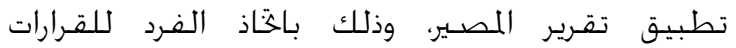

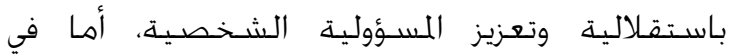

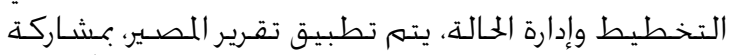

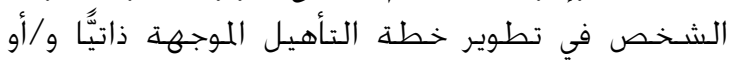
خطة الحياة المستقلة، وفي التطور المهني والوظيفي.

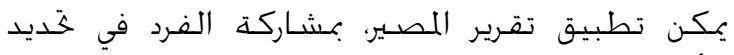

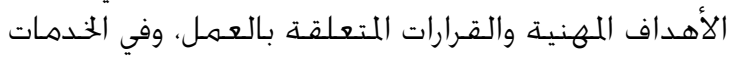

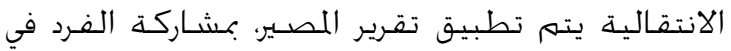

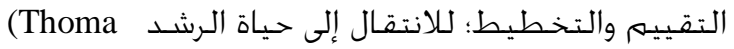
et al., 2003; Wehmeyer, Field, Doren, Jones \&

.Mason, 2004)

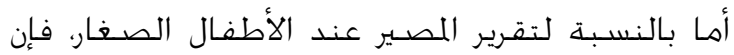

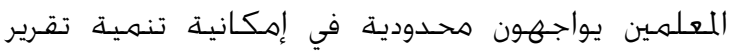

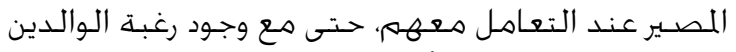

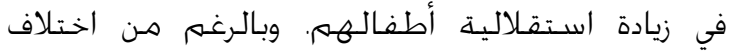
الدرجة التي يمكن أن يكون بها الأطفال الصغار ذيار ذوغ الصناف

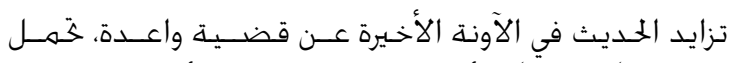

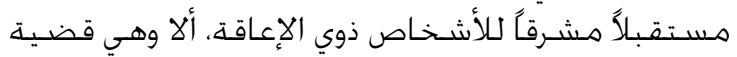

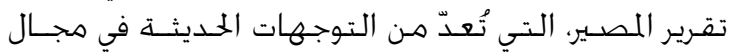

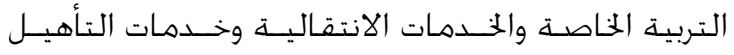

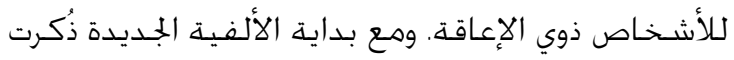

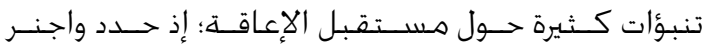
Wagner

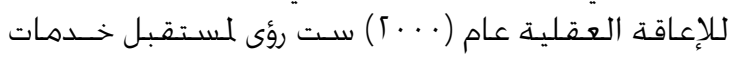

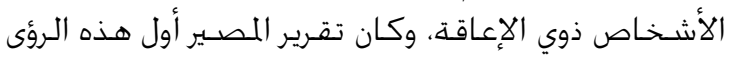
السـت (Taylor, Richards \& Brady, 2005).

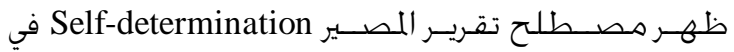

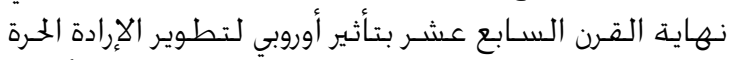

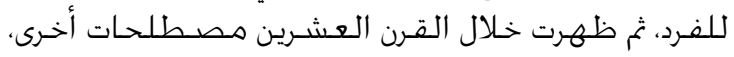

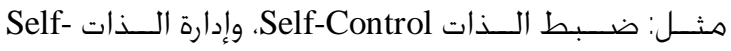
Management

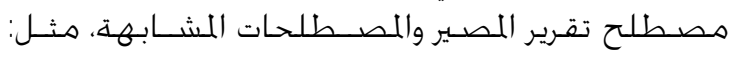

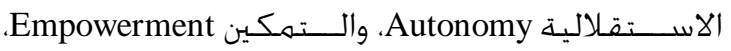

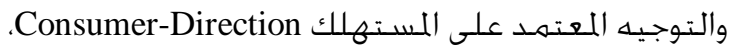

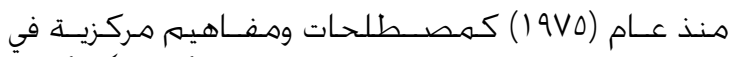

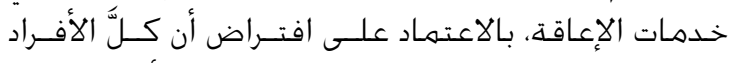

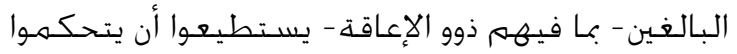

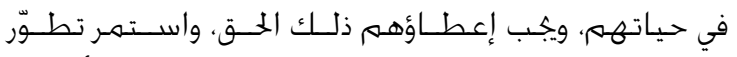

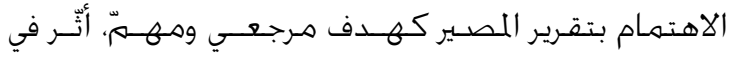

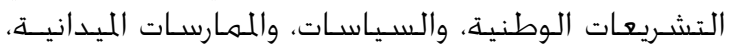

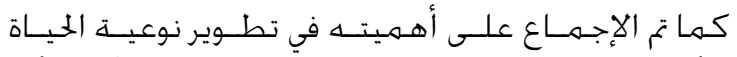

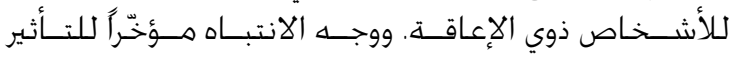

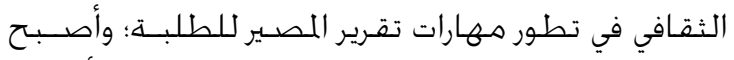

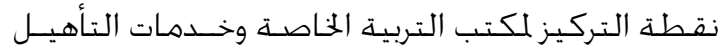
Office of Special Education and Rehabilitative Services (OSERS)

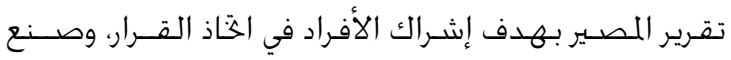

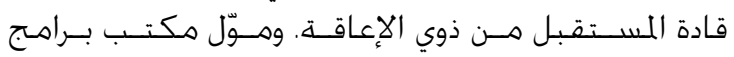

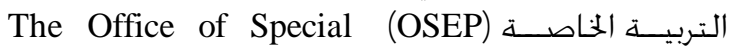
Education Programs

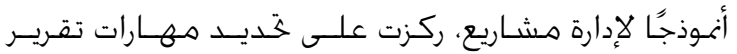

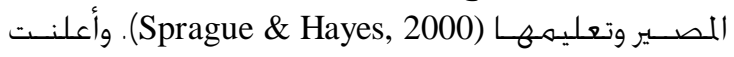

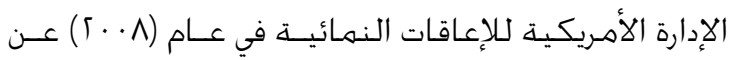

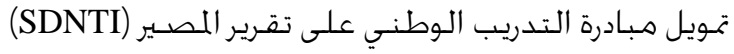

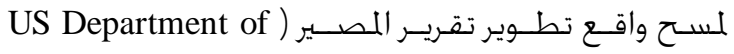

.(Health and Human Services, 2011

وعرّف قانون الإعاقات النمائية عام (...؟) نشاطات

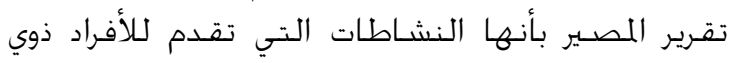

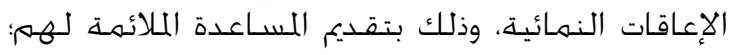

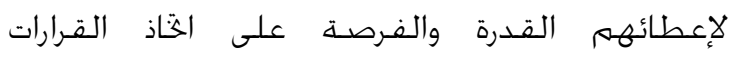
الشخصية، وإعطائهم فرصدة الاختيار وضبط نوعية الإنه 
وتغيرات البيئة، وبالرغهم مـن أن هذه النظرية تنسجهم هع

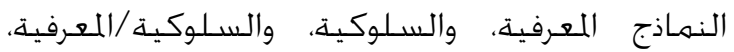

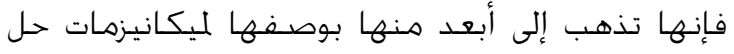

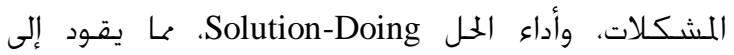

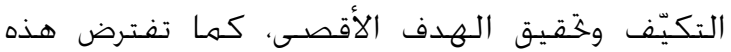

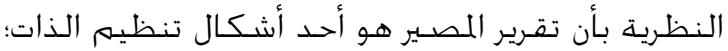

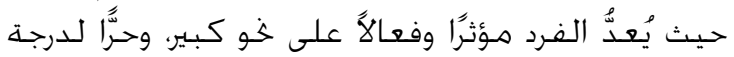

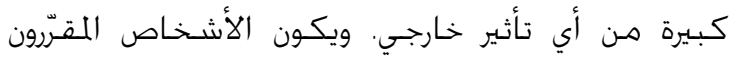

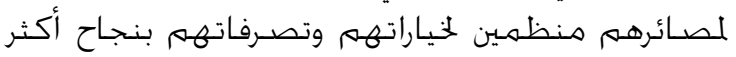

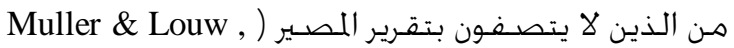

(2004

أما نظرية ديسي وريان (Deci \& Ryan) لتقرير المصـير Self-Determination Theory SDT

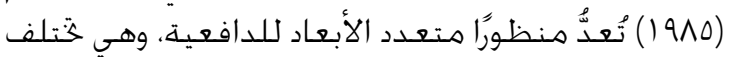

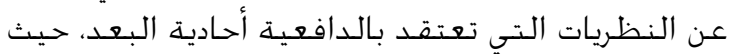

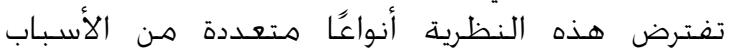

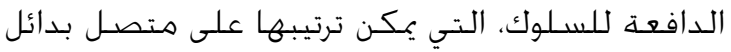

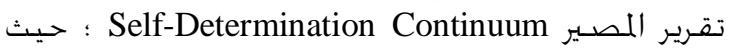

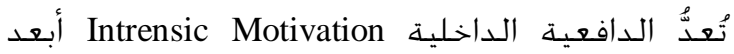

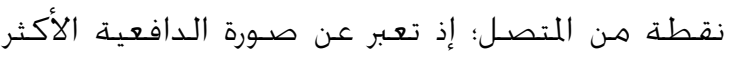

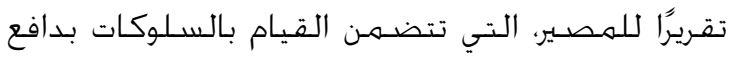

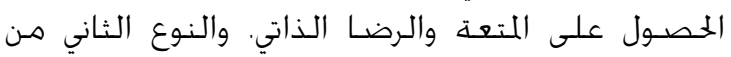
الدافعية هو الدافعية الخارجية Extrinsic Motivation

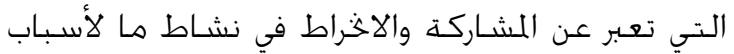

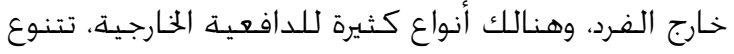

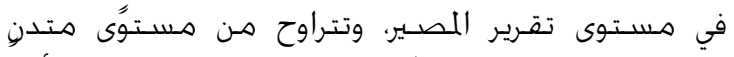

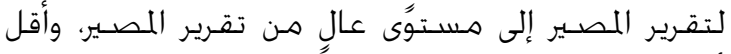

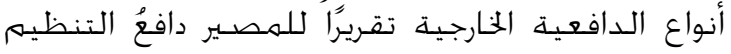

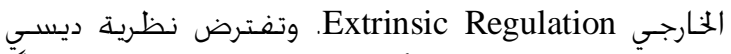
وريان Deci \& Ryan أن السـلوكات المدفوعة خـارجيًّ

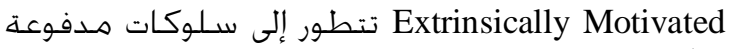

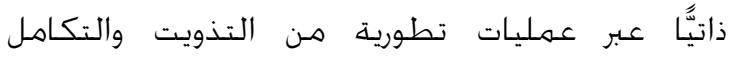
Internalization and Integration الفرد للعمليات التنظيمية التي هي خارجية إلى عمليات

تنظيمية داخلية (Muller \& Louw, 2004).

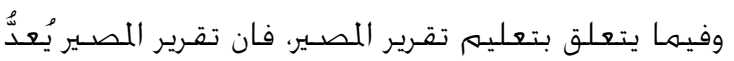

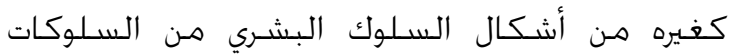

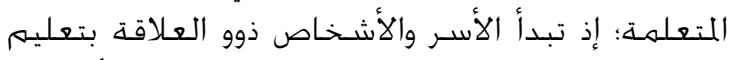

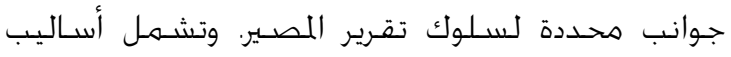

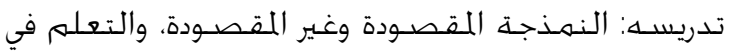

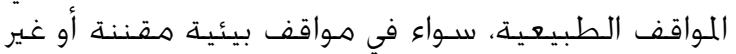

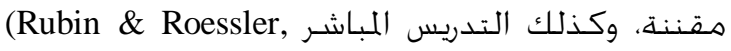
.1995; Lee, Palmer, Turnbull \& Wehmeyer, 2006) وقد أشـارت المقابلات التي أجراها سـيرفر (2000) Sarver

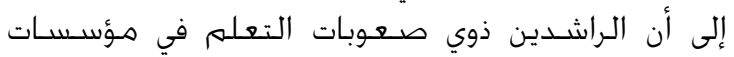

الإعاقة مقررين لمائرهـم، فإنّ المعرفة والمهارات

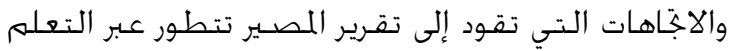

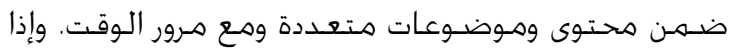

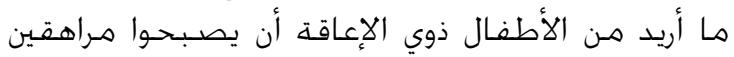

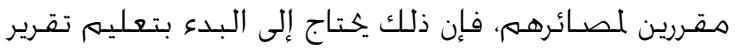

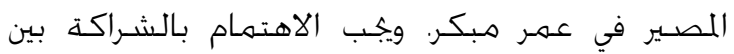
الأسـرة والاختصـاصسين لتحقيق نتائج إيجابية للأطفال

الصغار ذوي الإعاقة (Turnbull \& Turnbull, 2001).

تشـير الأبحاث إلى وجود علاقة بين المنحى البيئي لتقـرير

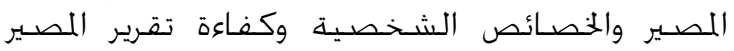

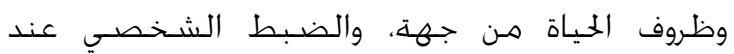

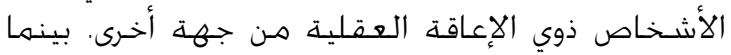

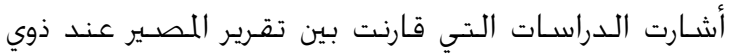

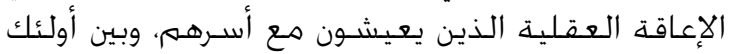

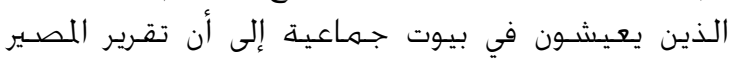

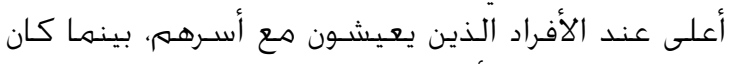

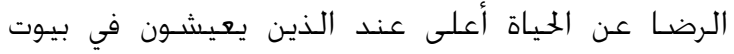

جماعية (Strnadova, and Evans, 2012).

هذا وقد ظهرت الكثير هـن النظريات المفســرة لتقـرير

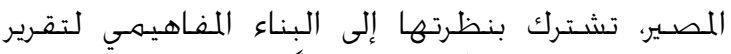

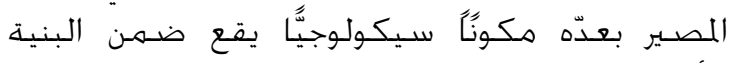

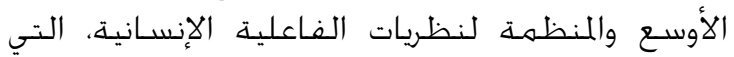
يقصد بها قدرة الفـرد على الاختيار وفرض خياراته

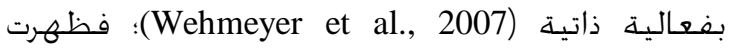

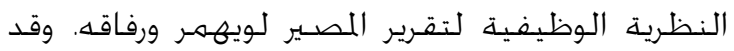

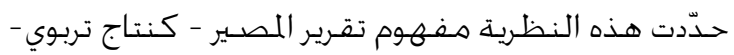

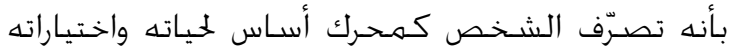

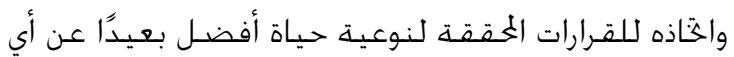
تأثير أو تدخل خارهل لـارجي (Gills, 2011).

أما النظرية البئية الاجتماعية theory لأبيري وستانكلف Abery and Stancliffe، فإنها

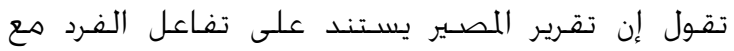

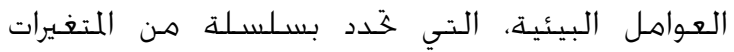

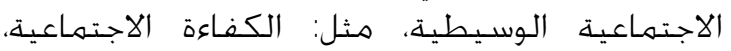

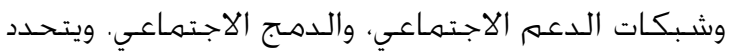

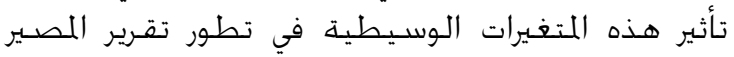

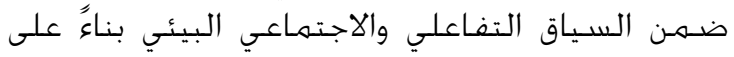

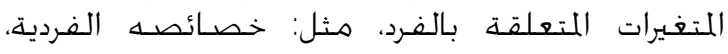

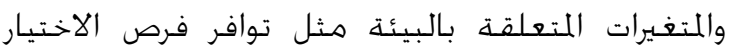

(Wehmeyer et al., 2007)

Self-Regulation كما ظهرت نظرية تنظيه الذات Theory تكّيف الأفراد لزيادة احتمالية وصـولهـم إلى ما يريدونه

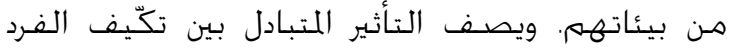




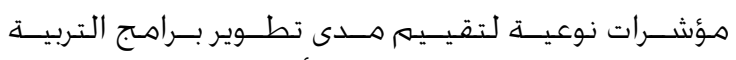

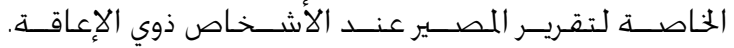

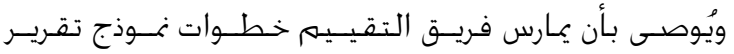

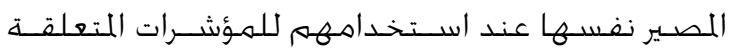

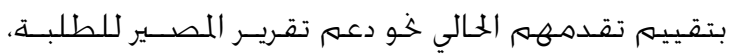

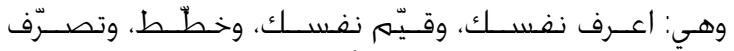

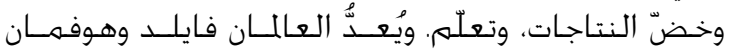
Field \& Hoffman

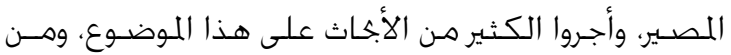

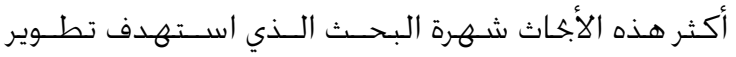

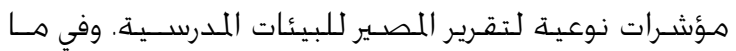
يأتي هـهـ المؤشـرات (Field \& Hoffman, 2002): تشـــــل المنـاهـج، وبرامهج دعــم الأســرة، وبـراهـج

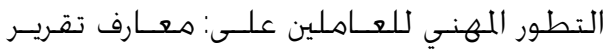

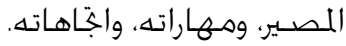

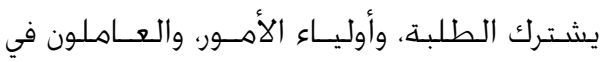

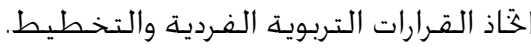

يوفر للططلبـة والأسـر والعاملين فرصًا للاختيار.

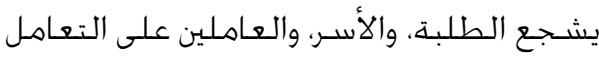
مع المواقف الجديدة.

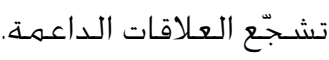

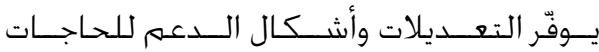
الفـردية.

يوفّر للطلبة، والأسـر، والكادر فرصـًا للتعبير عن

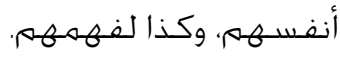

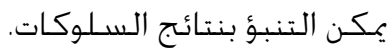

يتهم نمـذجـة تقـرير اللصسير في البيئة المدرسيـة.

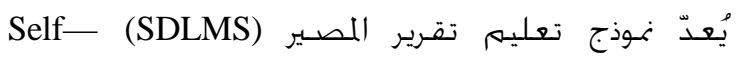
Determination Learning Model of Support موجهاًا لأولياء الأمور كي يطبّقـوه في البيت بهـدف تطوير

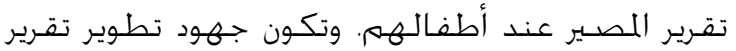

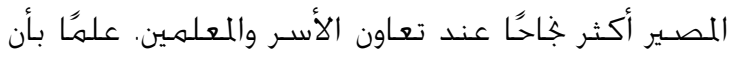

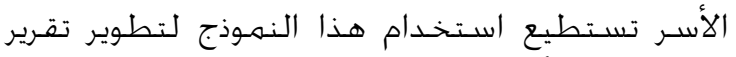

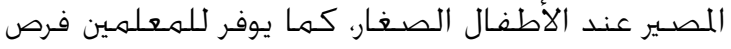

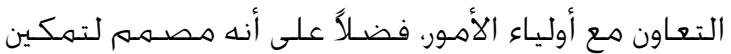

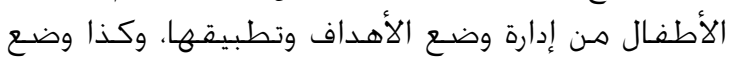

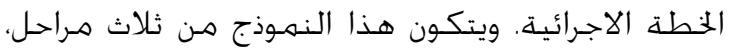

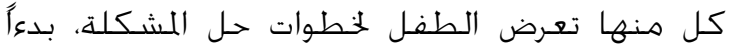

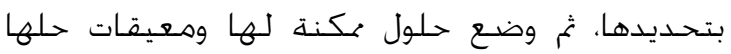

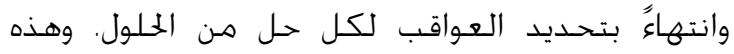
المراحل هي وضع الهدف، ثم خديد الخطة الإجرائية، وأخيراً

تعديل الخطة والأهداف (Lee \& Wehmeyer, 2004).
التعليهم ها بعد المرحلة الثانوية أشـاروا إلى الدور الكبير

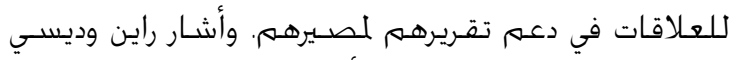
(Ryan \& Deci, 2000)

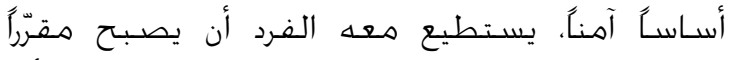

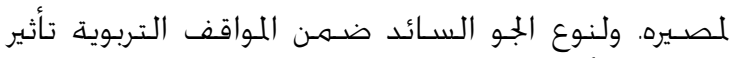

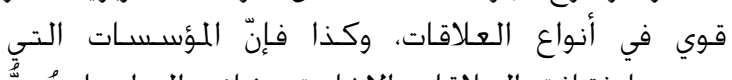

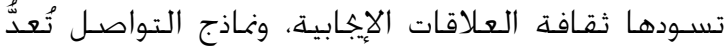

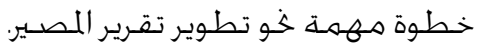

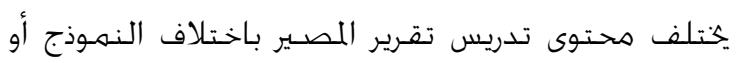

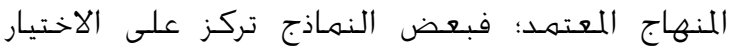

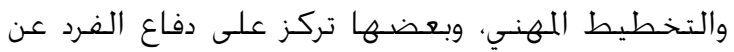

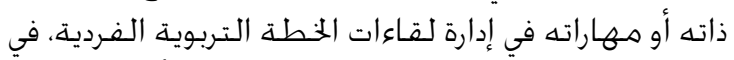

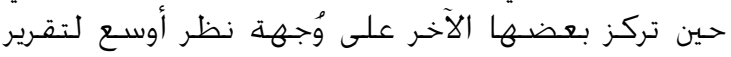

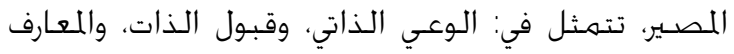

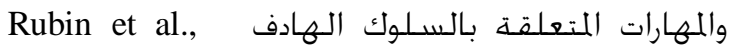

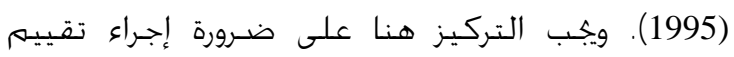

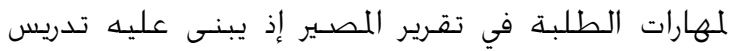

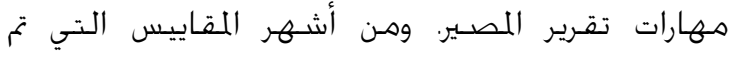

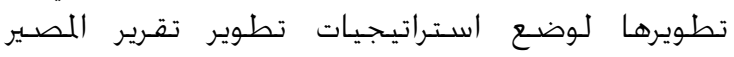

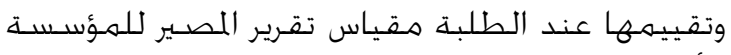

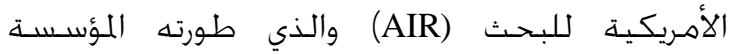
الأمريكية للبحتث الاهريكة في عام (AIR)

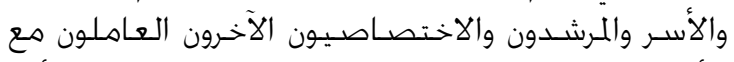
الأشخاص ذوي الإعاقة نتائج هذا المقياس لتقياسيهم أداء

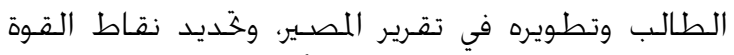

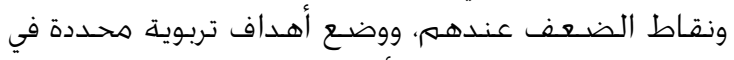
الخطة التربوية الفردية أو الخطة الانتقالية الفردية،

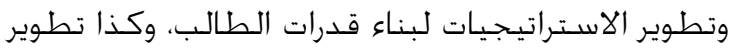

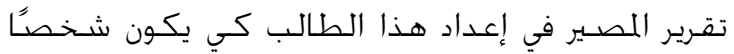
بالغًا أكثر استقـلالية (AIR, 1994).

ويشـتمـل تدريس تقـرير المصـير على تدريس قبول الفـرد

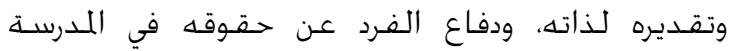

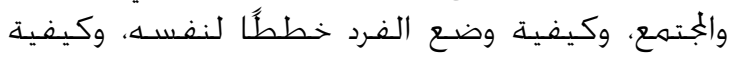

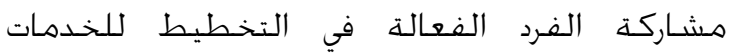

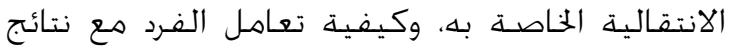

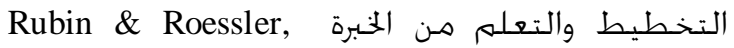

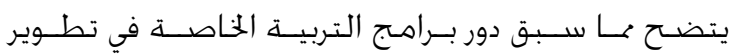

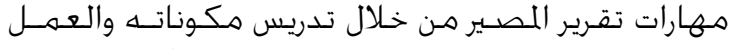

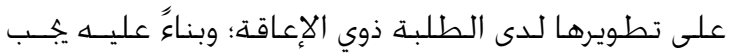

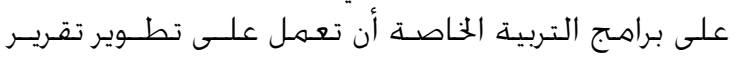

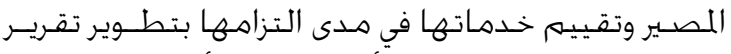

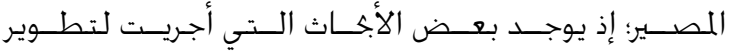




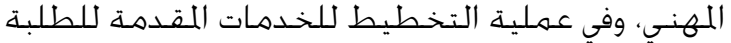

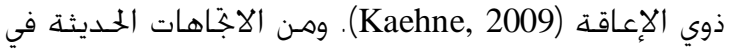

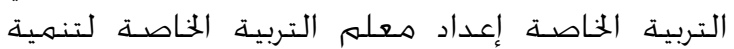

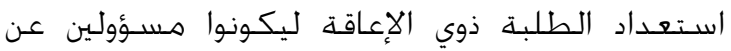

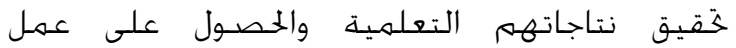

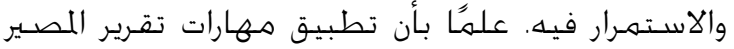
وتقييمها للطلبة ذوي الإعاقة، قد أصبـح جزءءًا أسـاستًا

من الخطة الفردية (Gills, 2011; Kaehne, 2009). وبنـاء على ما سـلف، ونتيجـة لإدراك أهـميـة تقرير المصـير

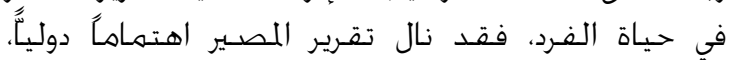

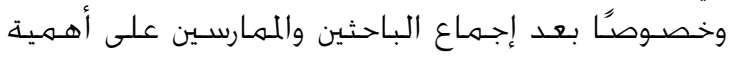

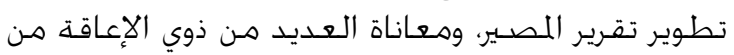

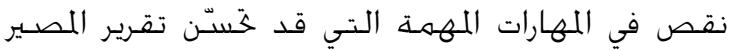

.(Carter, Pierson, Stang, 2008)

وهنالك دلائل كثيرة على اهتمام الباحثين والممارسـين

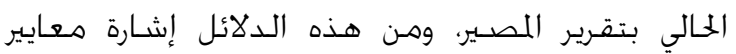

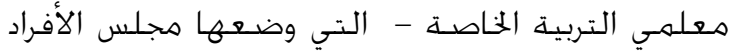

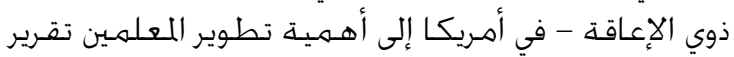
المصير عند الطلبة ذوي الإعاقة (Carter et al., 2008).

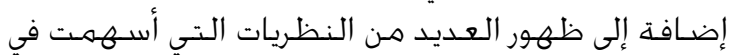

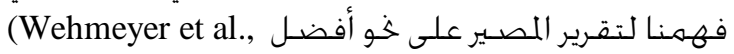

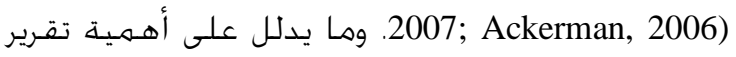

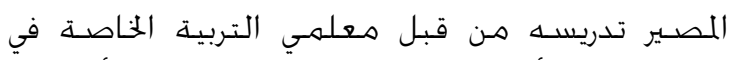

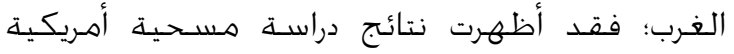

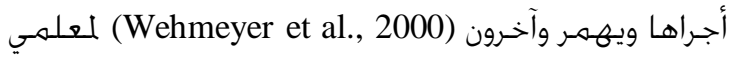

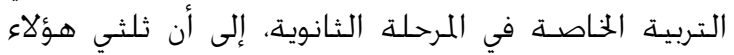

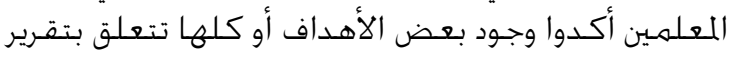

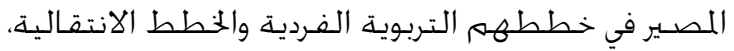

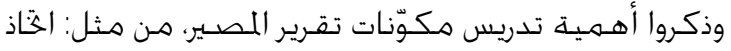

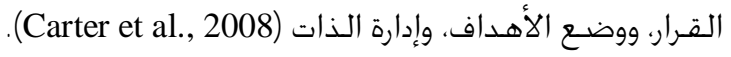

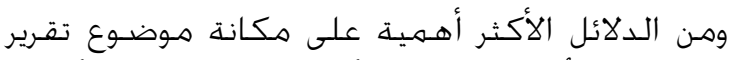

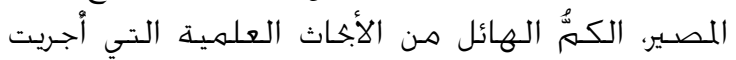

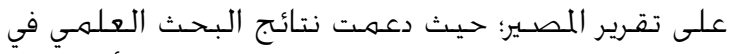

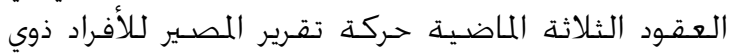

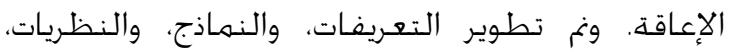

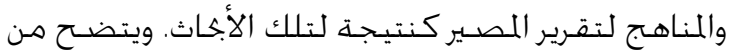

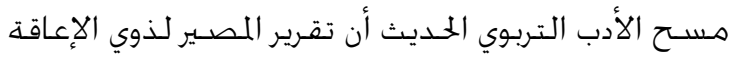

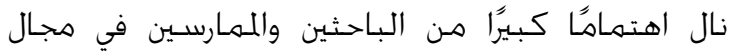

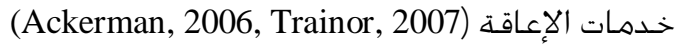

ولعل هـن أقوى دلائل أهـيـة تقـرير المصسير، والأكثر تأثيرًا

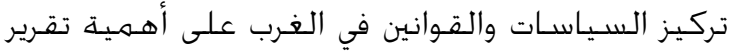

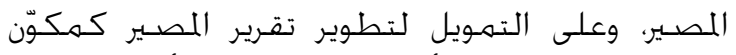

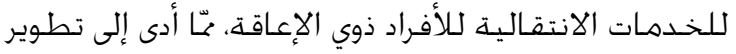

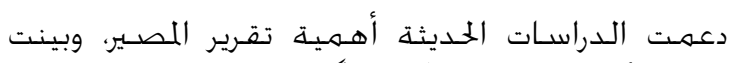

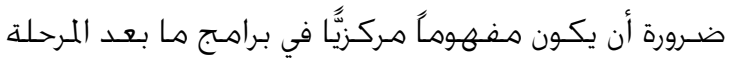

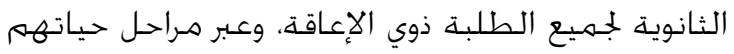

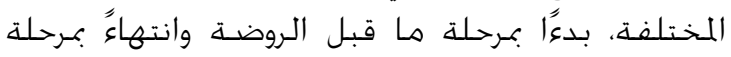
الرشــ (Field, Shaw \& Sarver, 2003). وأظهـرت

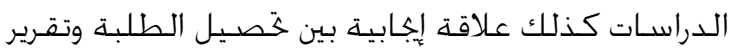

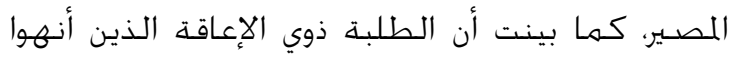

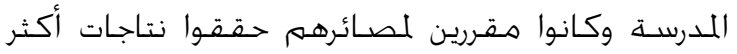

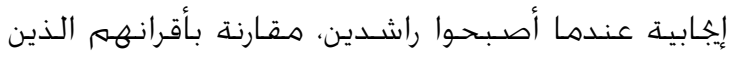

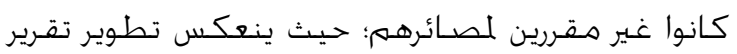

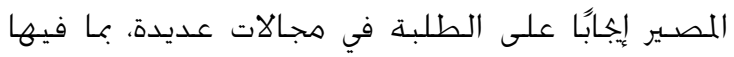
تطوير المشاركة في التخطيط التربوي ومهارات الدفاع المهاع عن الحقـوق وختسين القـدرات في بـدائل الـدمج، وأخيرًا

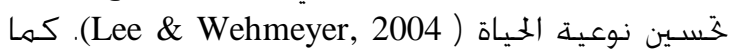

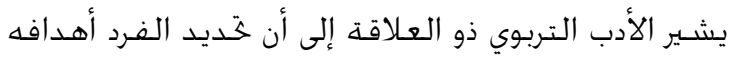

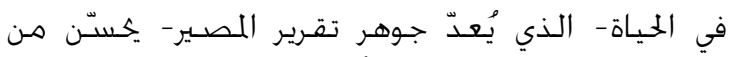

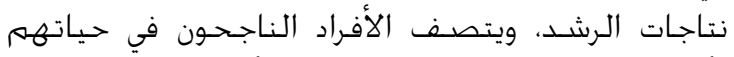

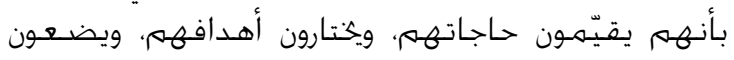

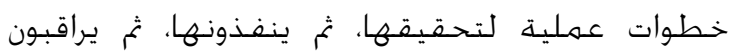

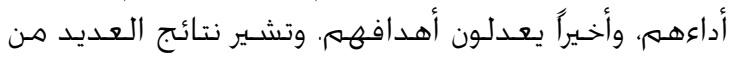

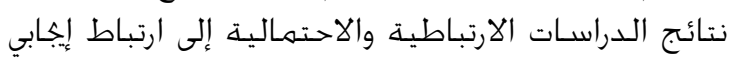

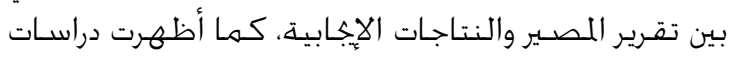

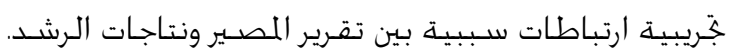

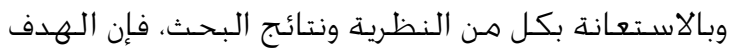

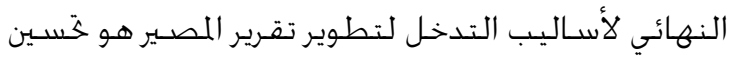

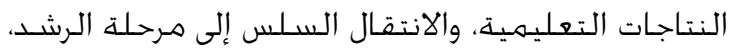

وختقيق الصـحـة النفسيـة الجيدة (Powers, 2010). إضـافة إلى إشـارة الدراسـات العلمية إلى وجـود علاقة قوية

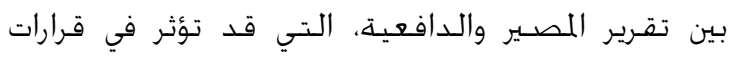

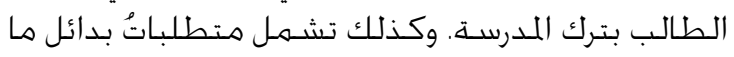

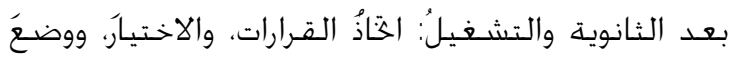

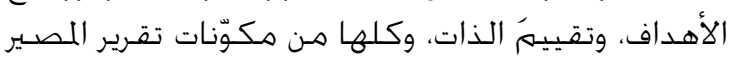

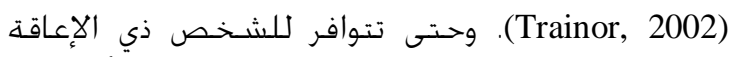

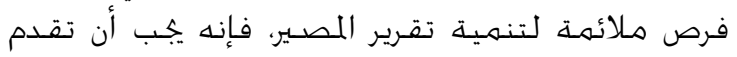

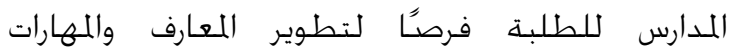

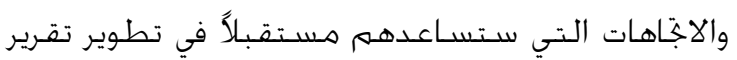

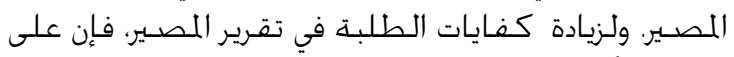

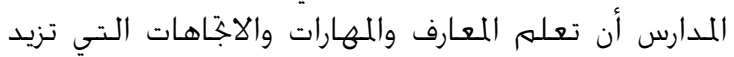

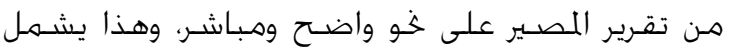

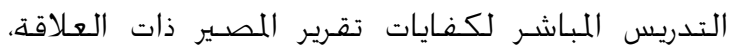

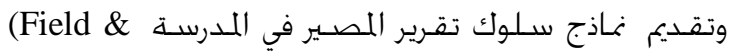
.Hoffman, 2002)

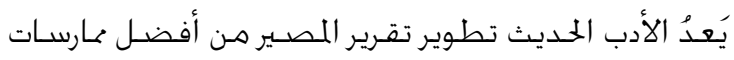

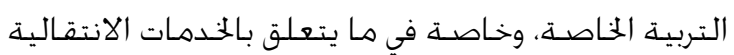

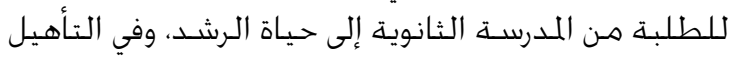


فئات الجُتهمع: التي هي في أشـدّد الحاجـة إلى تطوير مهارات

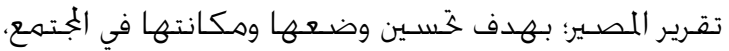
وكذلك خسين نوعيّة حياتها.

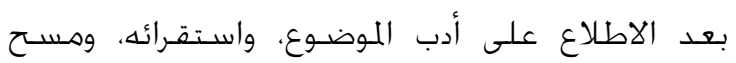

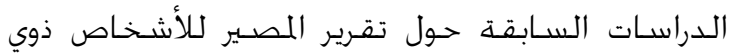

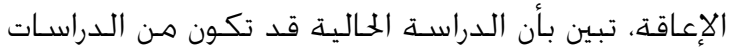

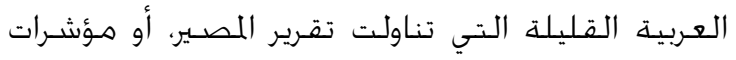

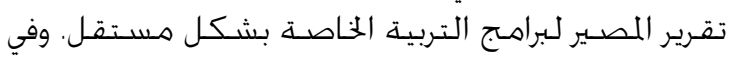

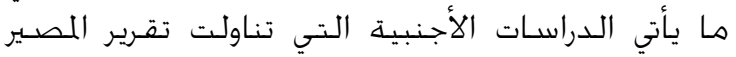

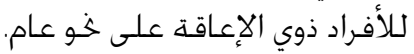
أجرى ديني Denney (2007) دراسـة هدفت إلى قياس تأثير

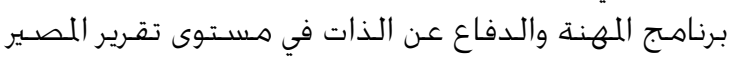

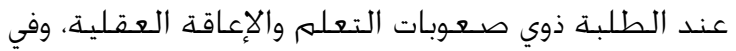

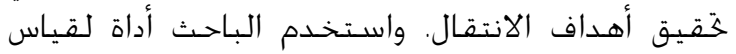

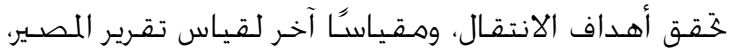

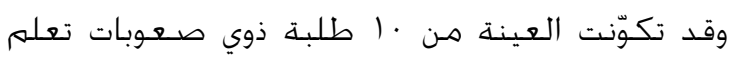

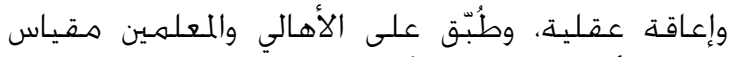

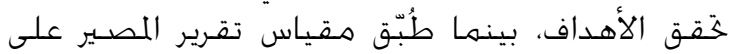
الوالدين والمعلمين والطلبة.

وأظهرت النتائج أن معظم الطلبة حققوا أهداف

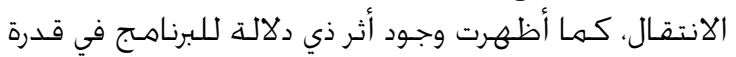

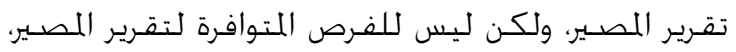

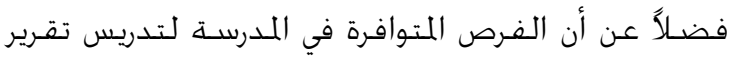

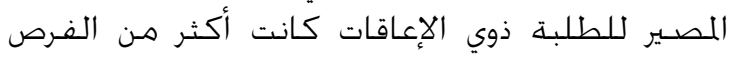

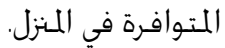

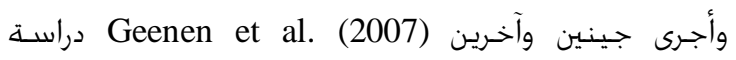
هدفت إلى معرفة أثر برنامج Foster Care

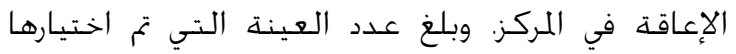

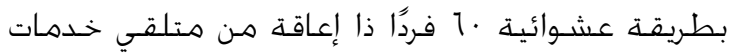

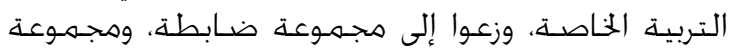

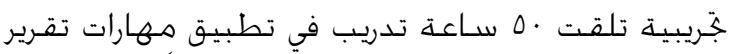

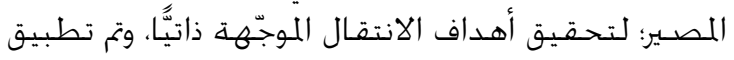

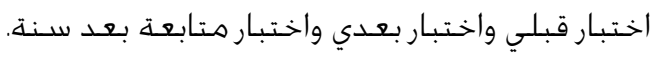
وقد أشـارت النتائج إلى وجود فروق في تقرير المصير ونوعية

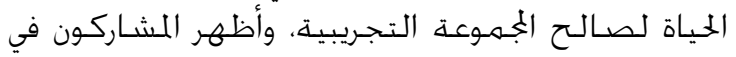

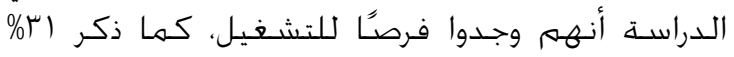

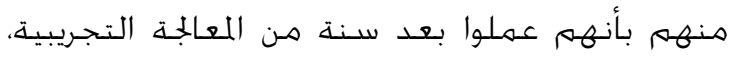

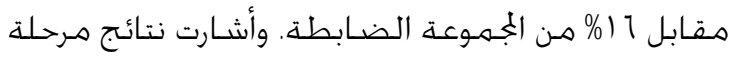

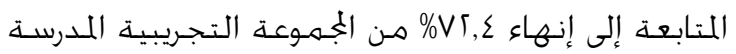

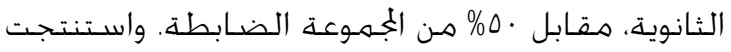

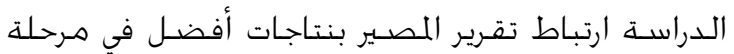

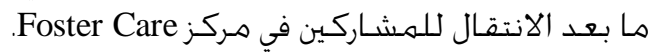

مصادر وإعداد مواد عديدة لدعم التدريس؛ بهدف خخقيق تقرير المسير (Wehmeyer \& Palmer, 2003).

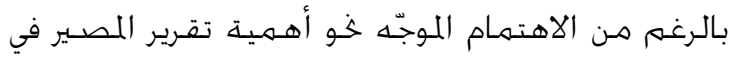

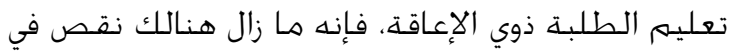

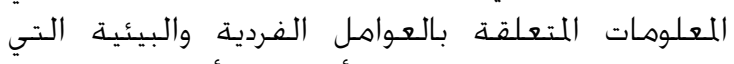

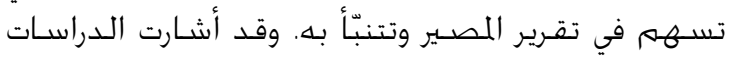

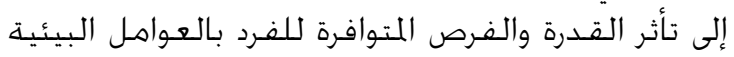
في تقرير المصير Shogren, Wehmeyer, Little, Garner (\& Lawrence, 2007)

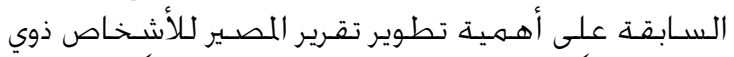

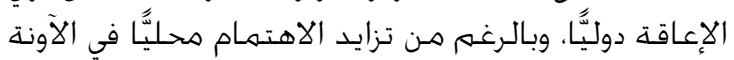

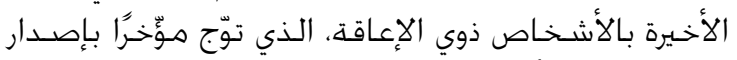

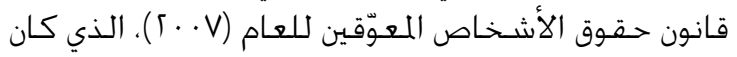

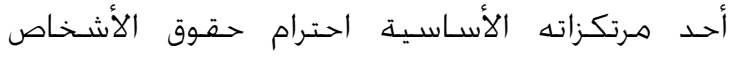

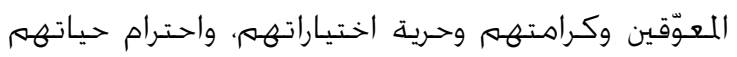

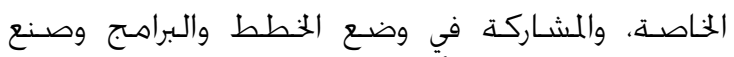

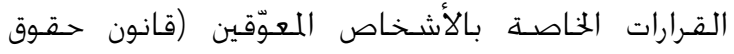

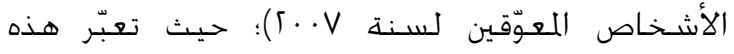

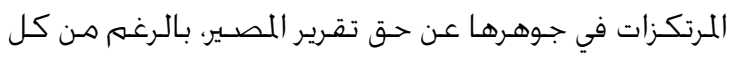

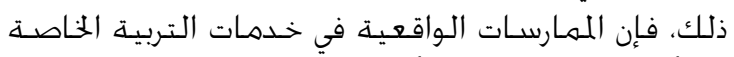

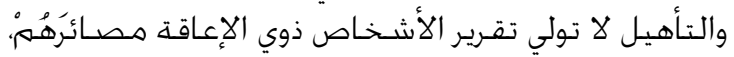
واحترامَ اختياراتهـم، وحياتهم الخاصـة الاهتمامَ الكافي.

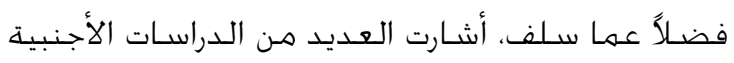

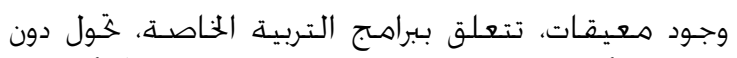

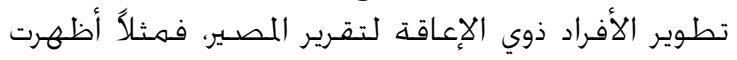

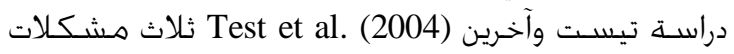

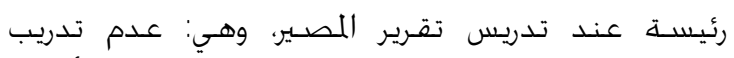

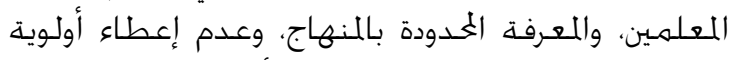

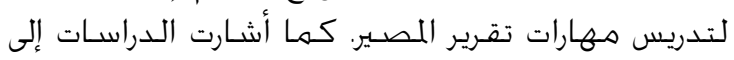

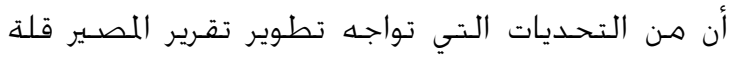

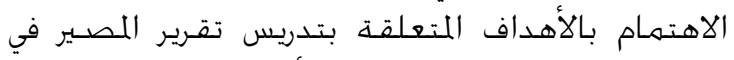

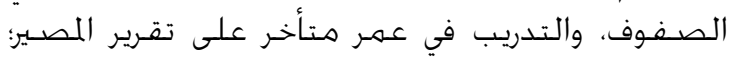
حيث لا يتلقى الطلبة التدريب إلا في المرحلة الثانوية.

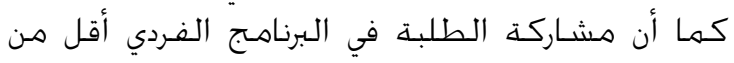
المتوقع (Martin, Van Dycke, Greene, Gardner, \& Johnson, Stodden, وجد جونسـون ورفاقه.Lovett, 2006 (Emanuel, Luecking, \& Mack, 2002)

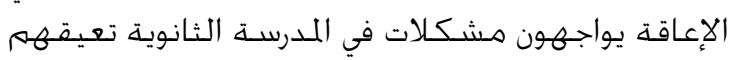

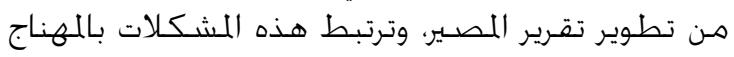

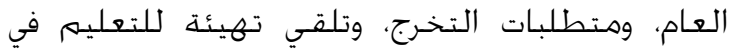

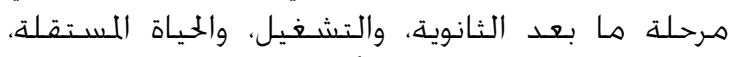

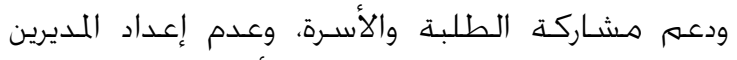

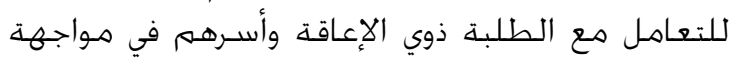

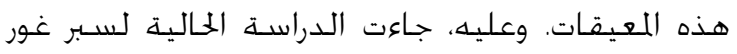

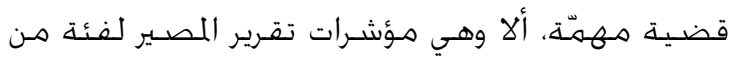


وأشارت النتائج إلى أن الفرد ذا الإعاقة نادرًا ما يكمهل

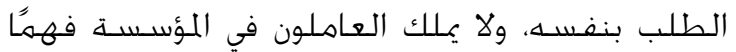

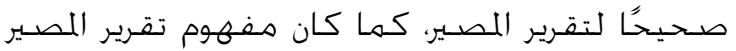

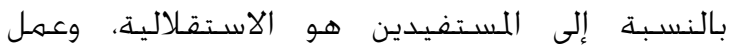

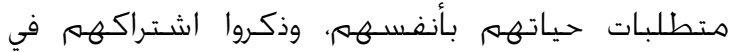

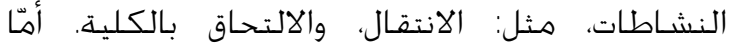

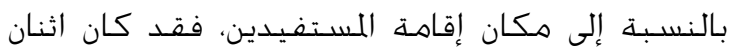

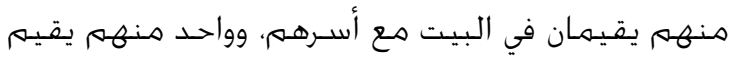

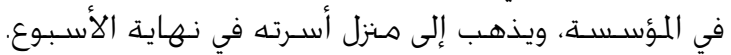

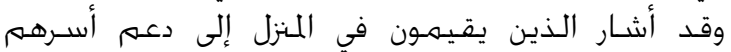

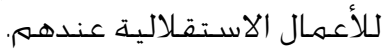

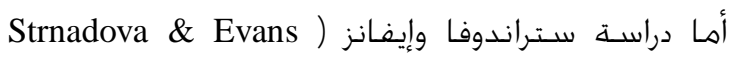
2012) فقد هدفت إلى تعرّف إدراك النسـاء ذوات الإعاقة

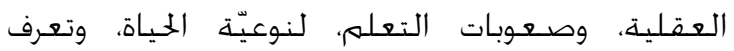
مستوى تقريرهن لمسيرهن، وهعيقاته، وكذلك تعرّف إلته الفروق في إدراك نوعيّة الحياة بين النسـاء ذوات العيد الإعاقة

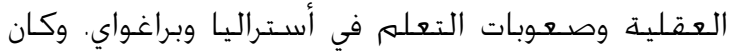

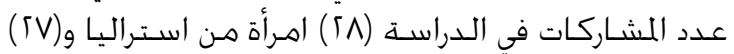

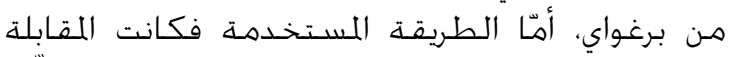

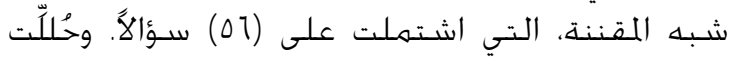
البيانات وصنفت باستخـدام منـحى النظرية المجذرة.

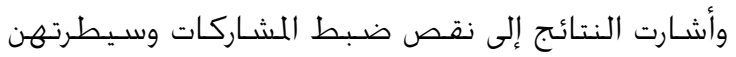

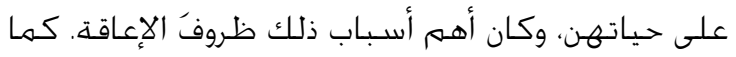

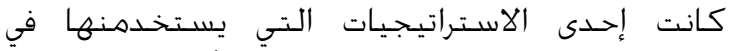

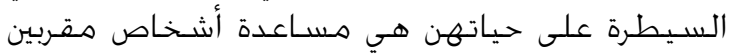

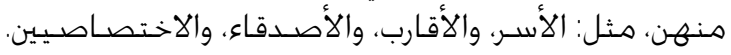
وتشابهت نوعية الحياة بين المشاركات ذوات واتلات الإعاقة

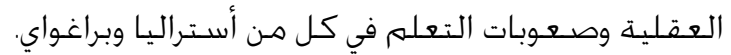

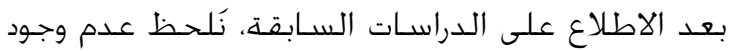

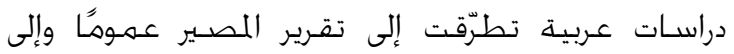

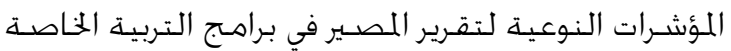

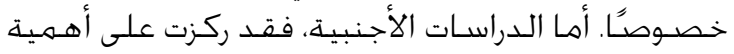

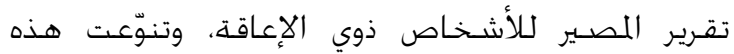

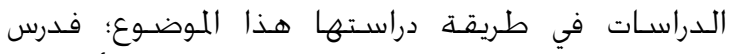

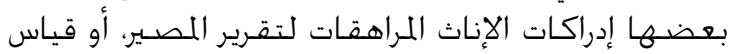

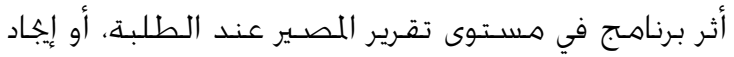

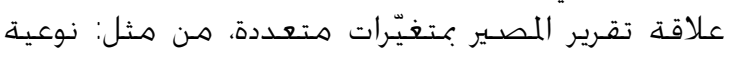

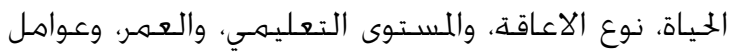
تتعلق بالتشغيل، وغيرها.

أما الدراسـة الحالية، فهي تلتقي هع بعض الدراسـات

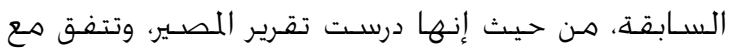

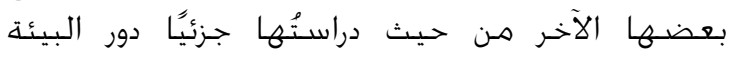

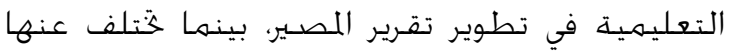

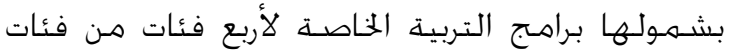

Verdugo, Martin-Ingelmo, كما أجرى فيرديجو وآخرون دراسـة هدفت إلى تعرّف أثر أحد

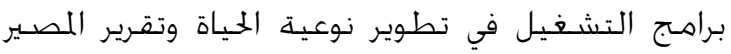

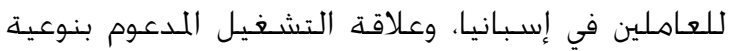

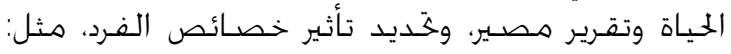

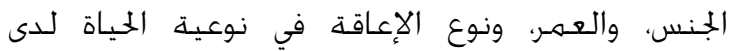

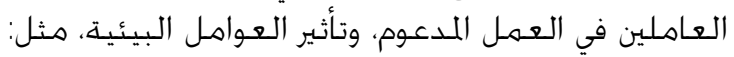

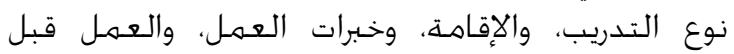

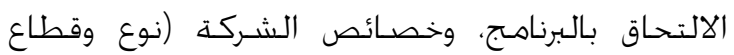

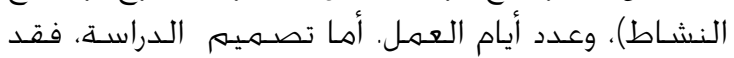

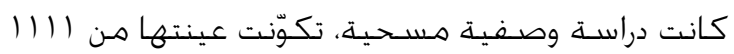

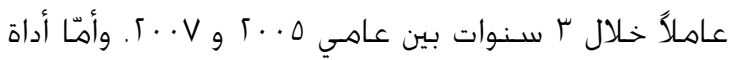

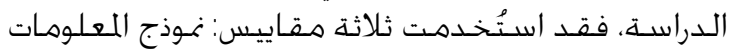

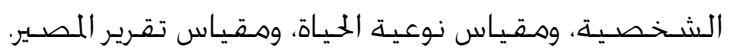
وأشارت النتائج إلى وجود فـروق دالة في المتغيَّرات

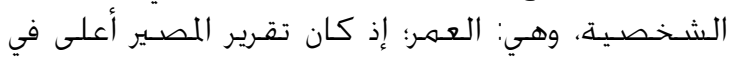

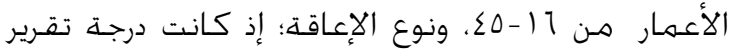
المسير أقل لذوي الإعاقة العقلية مقارنة الإنة الإعاقات

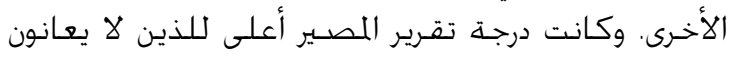

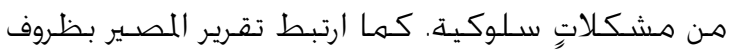

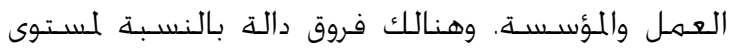

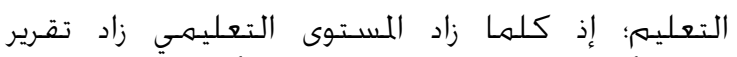

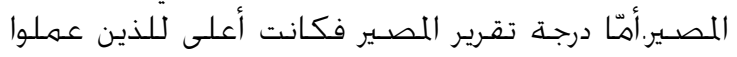

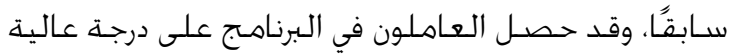

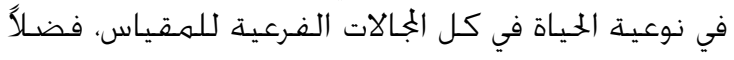

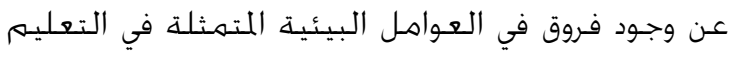

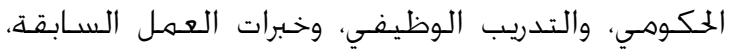

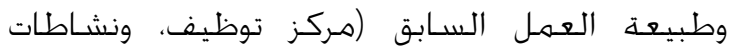

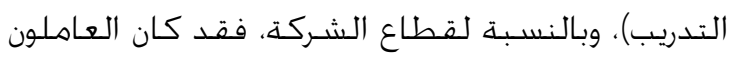

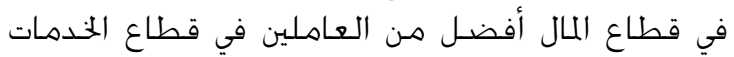

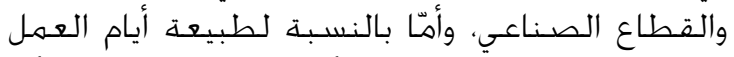

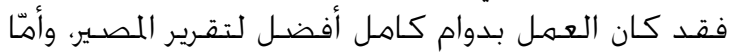

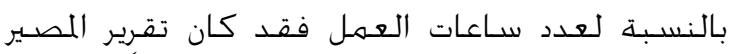

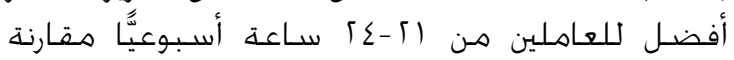

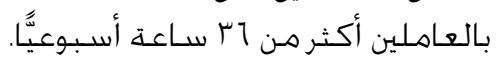

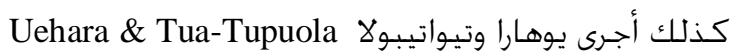

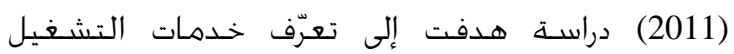

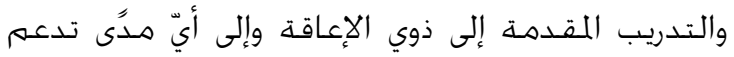

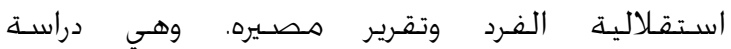

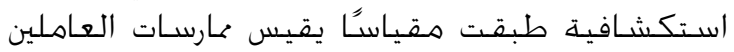

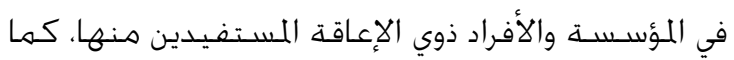

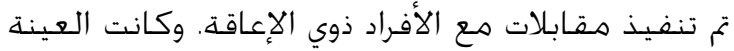

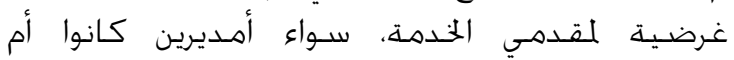

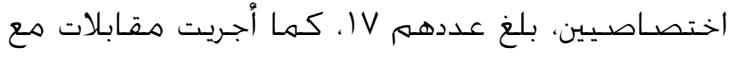

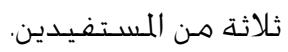




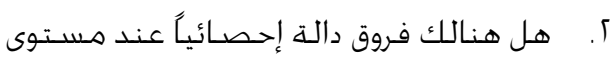

الدلالة ه ., في هستـوى انطباق المؤشـرات

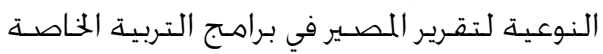

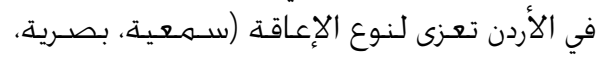

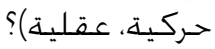

\section{أهمية الدراسـة}

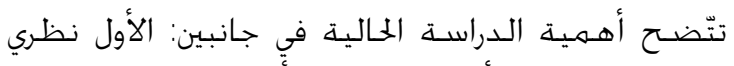

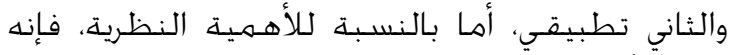

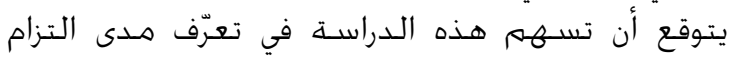

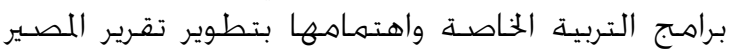

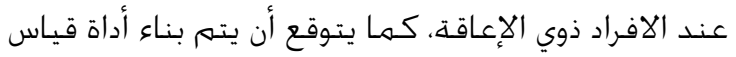

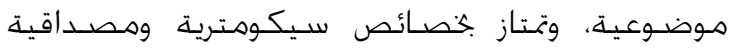

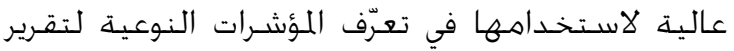

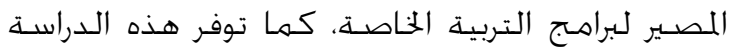

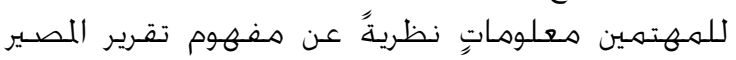

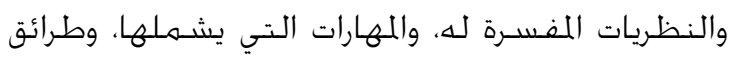

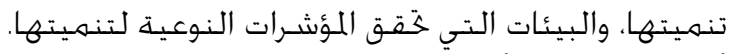

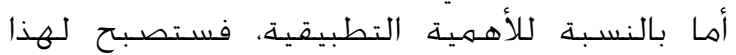

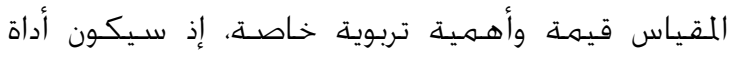

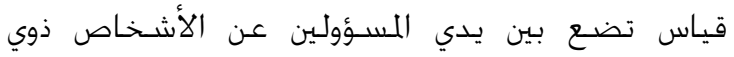

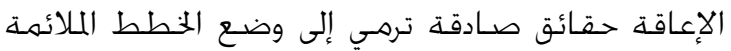

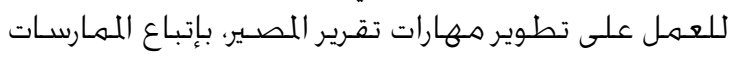

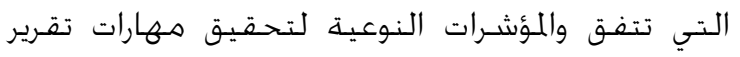

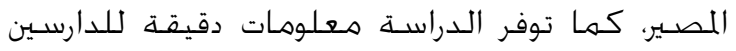

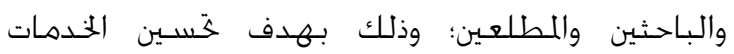

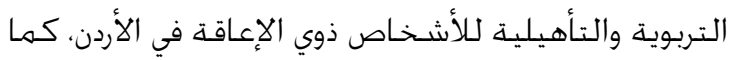

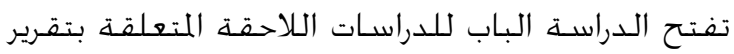
المسير.

\section{حدود الدراسـة ومحدداتها}

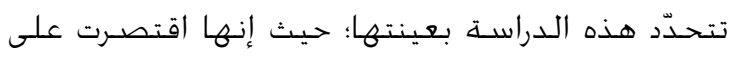

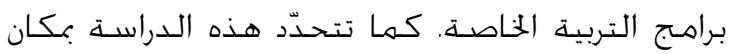
إجرائها: حيث أجريت في مراكز التربية التربية الخاصـة في الأردن.

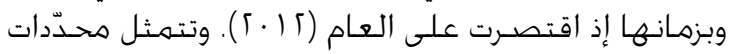

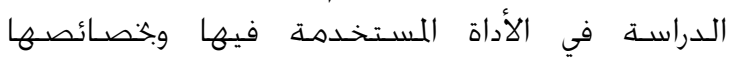
السيكومترية، وفي الدقة في جهمع البيانات.

\section{الطريقة والإجراءات}

\section{منهج الدراســــ}

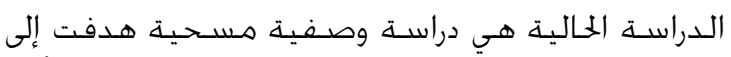
تعرّف مستوى التزام براهـج التربية الخاصـة في الأردن التين بالمؤشرات النوعية لتقرير المسير.

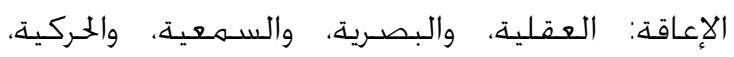

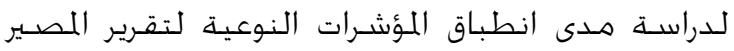

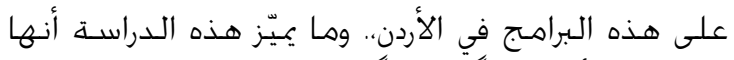

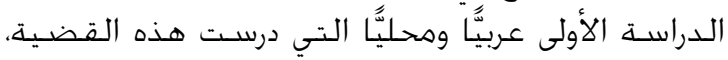

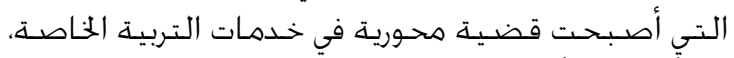

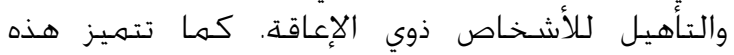

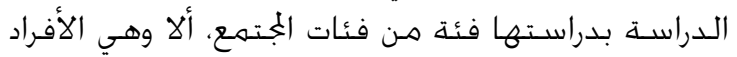

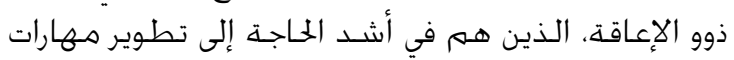

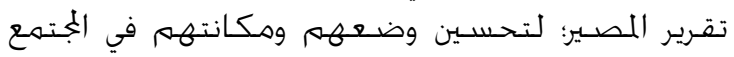

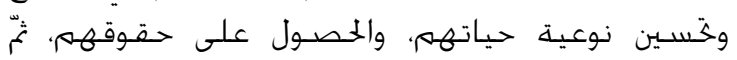
دفاعهم عنها.

\section{مشكلة الدراسـة وهدفها وأسئلتها}

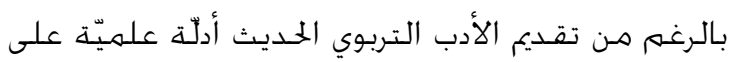

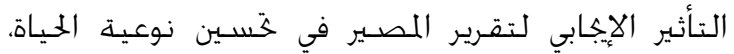

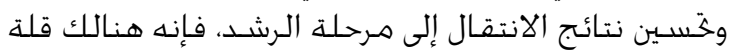

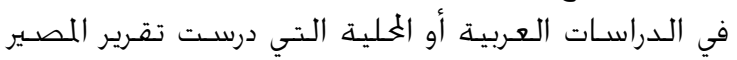

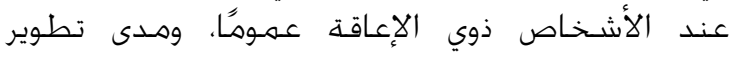

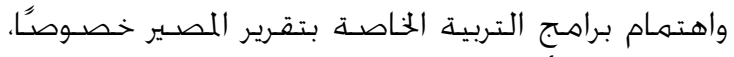

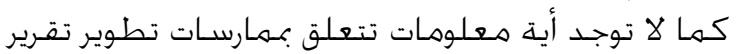
المسير في برامهج التربية الخاصـة في الأردن.

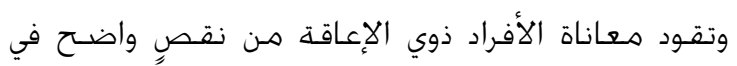

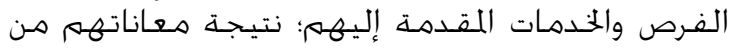

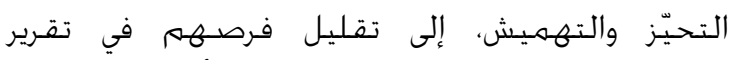

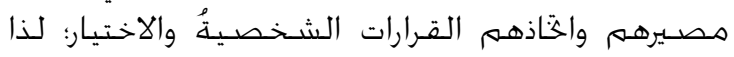

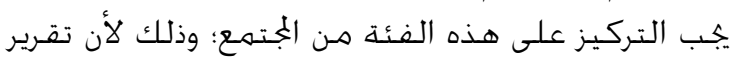

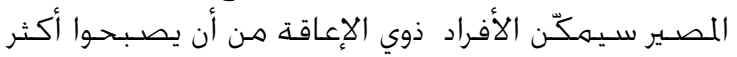

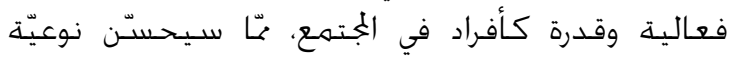

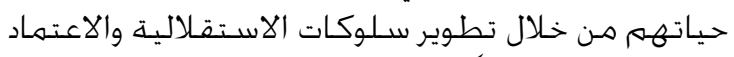

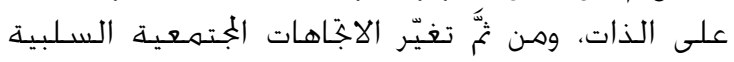
المتمثلة في النظرة النمطية السائدة للأفراد ذوي الإعاقة بأنهم أقل قيمة وفعالية.

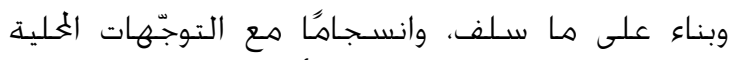

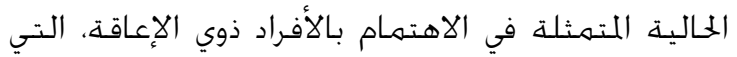

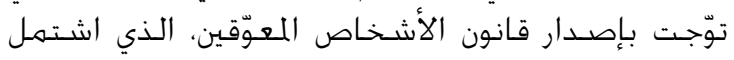

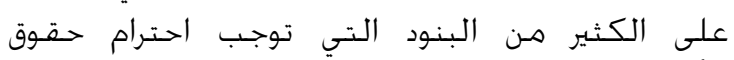

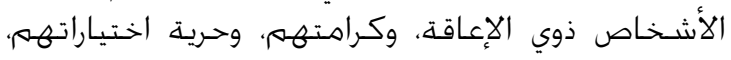

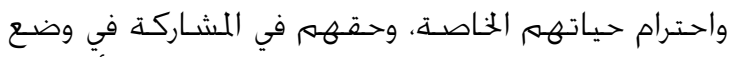

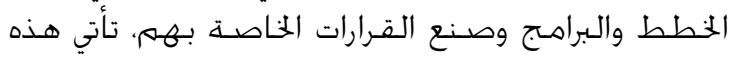

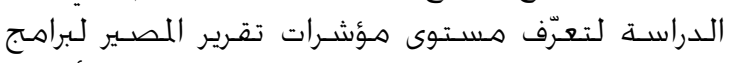

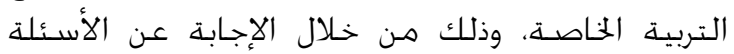

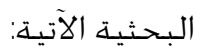

ا. . ما مسـتوى انطباق المؤشـرات النوعيــة لتقريـر

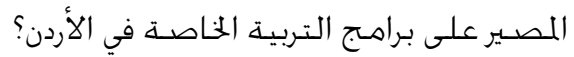




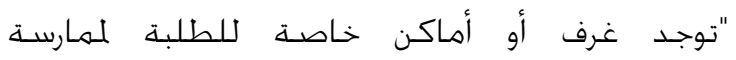

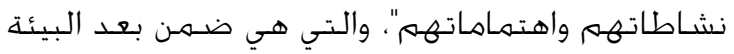

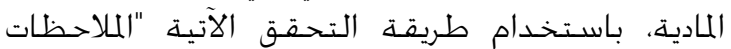

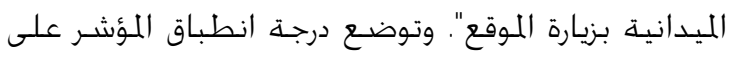

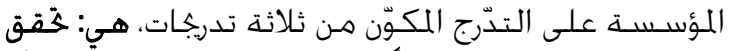

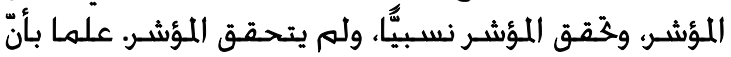

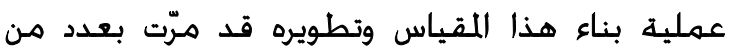
المراحل، هي:

'. مـراجعة الأدب التربوي حول أبعاد المؤشـرات النوعية

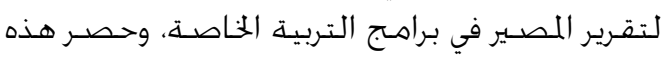
(Field \& Hoffman, 2002; الأبعاد وتعريفهـا إجرائيا. .(O'Brien, Revell, \& West, 2003

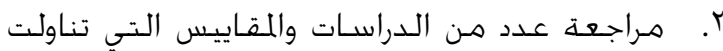

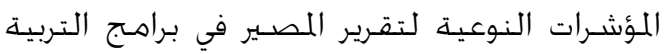

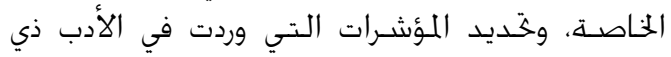
العلاقة.

(Field \& Hoffman, 2002; O'Brien, Revell, \& West, 2003; Field, Sarver \& Shaw; 2003; Field, \& Hoffman, 1994; Kipp \& Amorose, 2005)

r. وضـع مؤشـرات لكـل بعـد مـن الأبعاد الرئيسـة، بحيث تمّت صـياغـة · 1 مؤشـرًا.

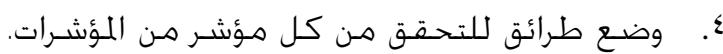

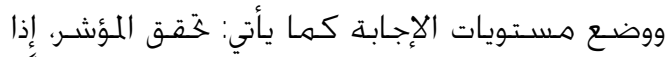

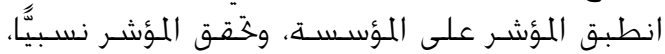

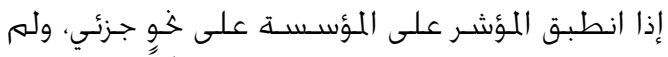
يتحق المؤشـر، إذا لم ينطبق المؤشئر نـهائيًا.

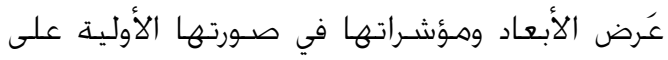

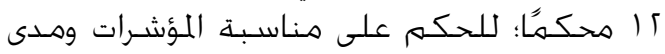

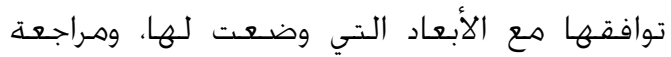

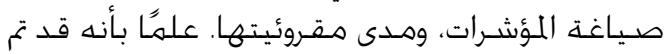

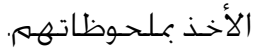

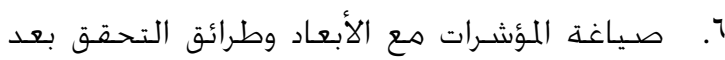
الأخذ بملحوظاتهمه المؤهرات مع

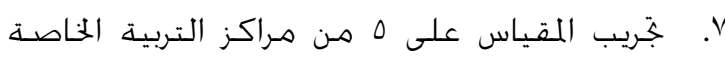

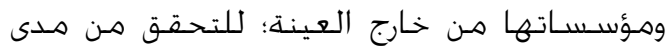

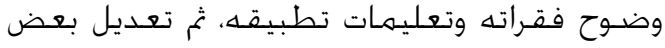

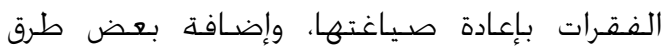

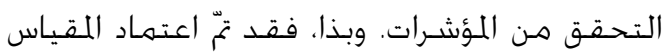

$$
\text { بصـورتـه النهائية. }
$$

صـدق المقياس وثباته

للتحقق هـن صـدق مقياس المؤشـرات النوعية لتقـرير

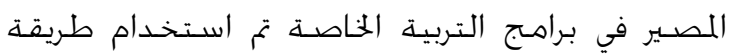

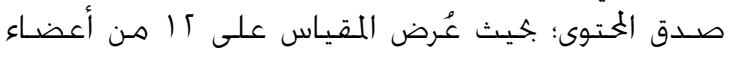

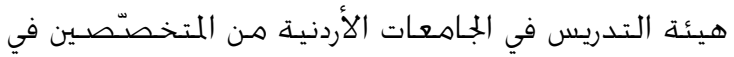

\section{مجتمع الدراسـة، وعينتها}

يتألف مجتمع الدراسـة الخالية مـن جـميع مـراكز التربية

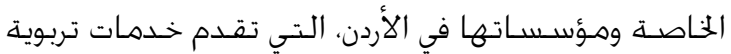

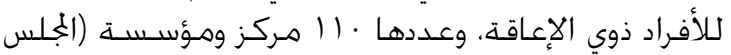

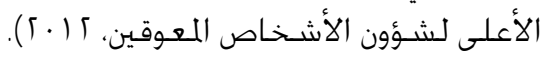

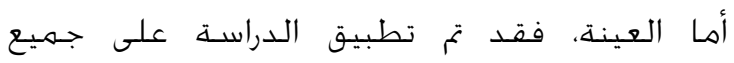

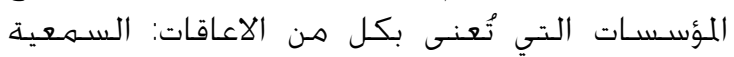

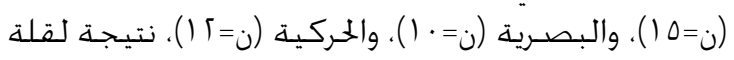

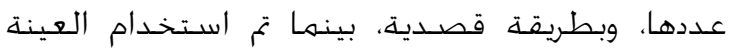

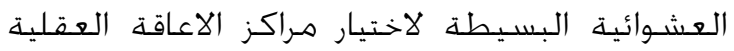

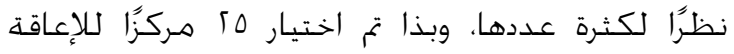

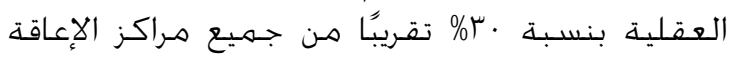

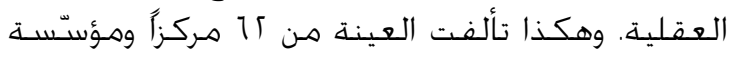
هـن مـراكز التربية الخاصـة ومؤسـسـاتها.

أداة الدراســـ مراس

لجمع البيانات، طوّر الباحثان مقياس المؤشـرات النوعية

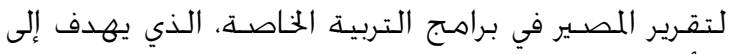

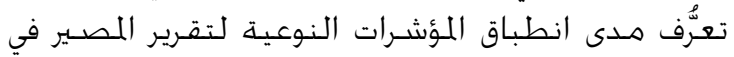

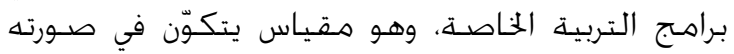

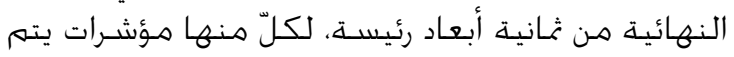

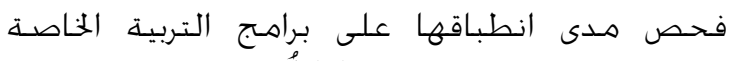

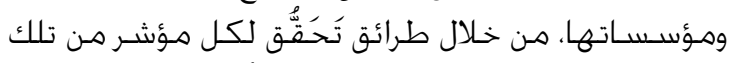

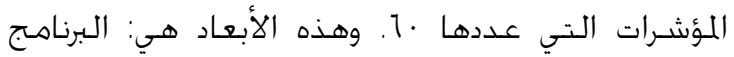

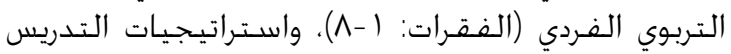

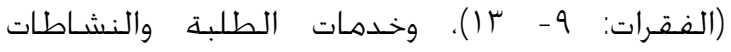

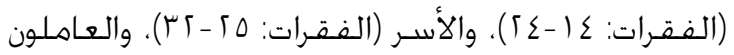

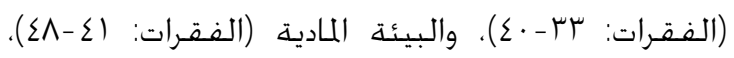

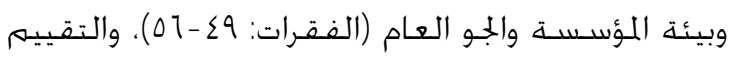

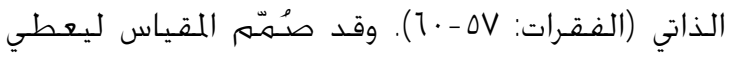

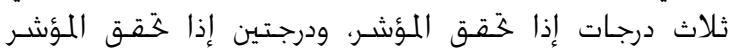

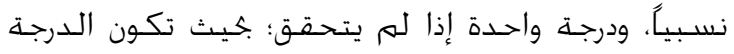

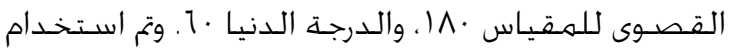

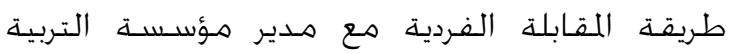

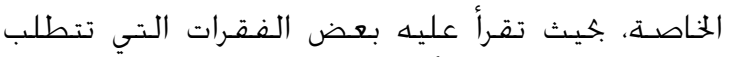

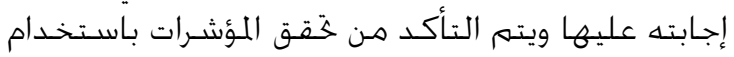

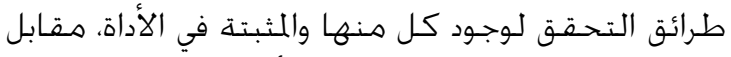

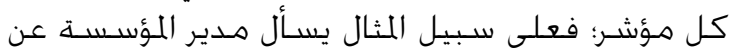

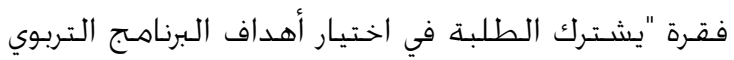
الفـردي"، والتي تقـع ضـهـن بعـد البرناهـج التربوي الفـردي.

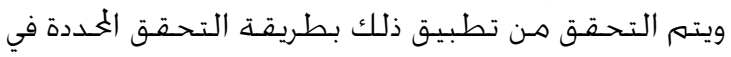

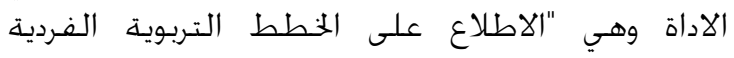

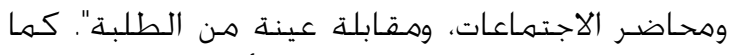

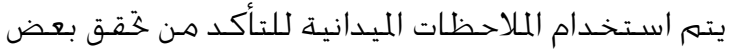

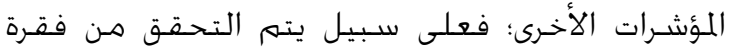


أعـدّ الباحثان مقياس الدراسـة لجمع البيانات مـن عينـة الدراسـة.

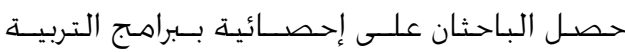

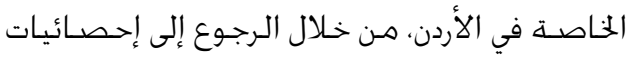

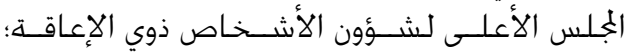
وذلك لتحـديد حجهم مجتهمع الدراسـة وعينته.

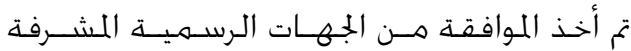
على برامـج التربية الخاصــة في الأردن، وهـما وزارتـا

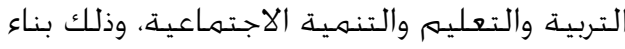
على كتاب رسـمي مـن الجامعـة الأردنية.

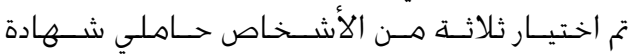

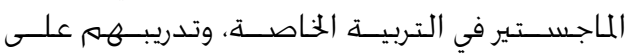
اللقياس وآلية تطبيقهـ للمسيـاعدة في تطبيقهـ.

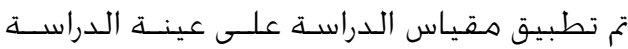

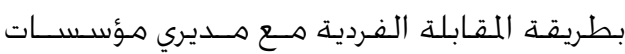

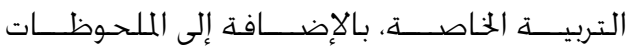
الميدانية.

\section{المعالجة الإحصائية}

للإجـابة عن ســؤالي الدراســـة تم اســتخـدام المتوســــات

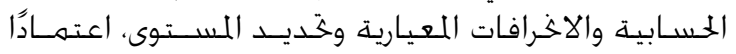

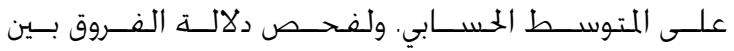

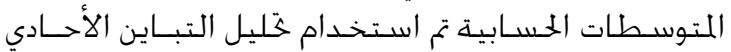
ANOVA

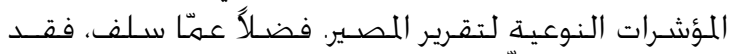

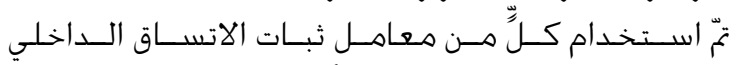

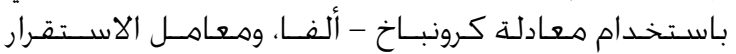
لتعرّف ثبات المقياس.

\section{النتائج}

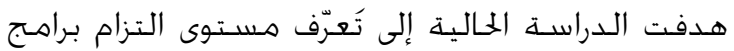

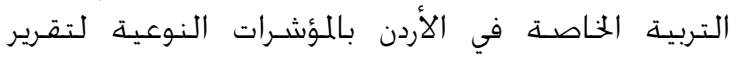

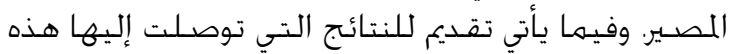
الـدراسـة. الإجابة عن السؤال الأول، وهو: ما مسـتوى انطباق

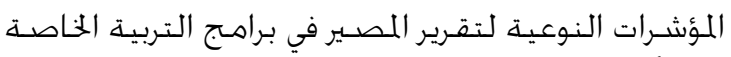
في الأردن؟

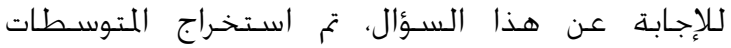

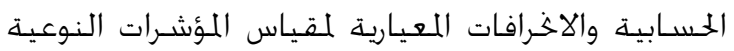

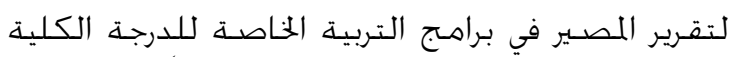

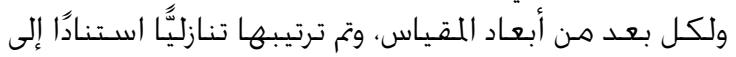

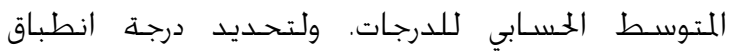

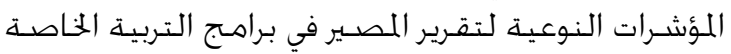

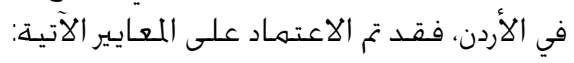

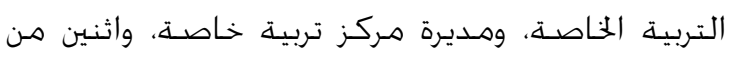

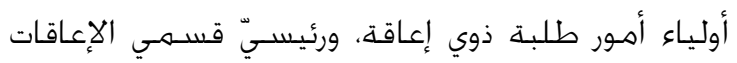

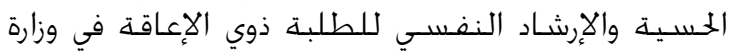

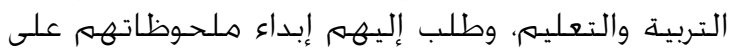

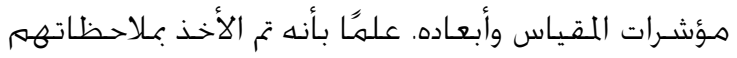

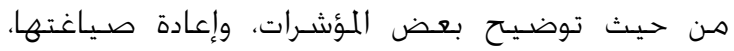

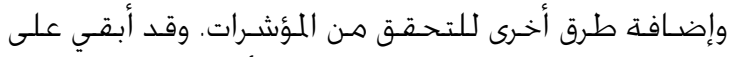

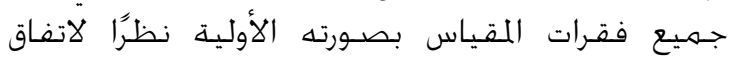

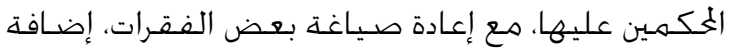

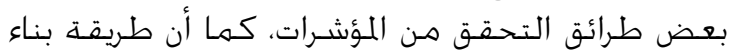

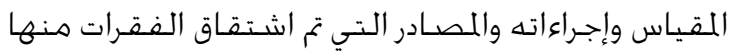

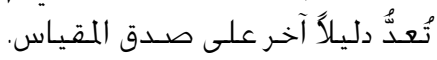

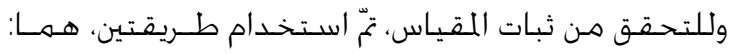

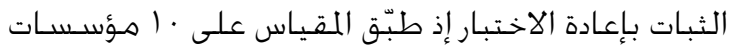

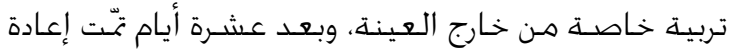

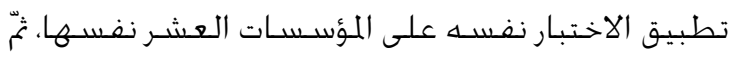

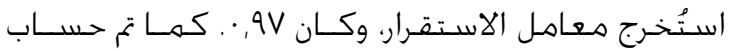

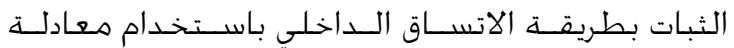

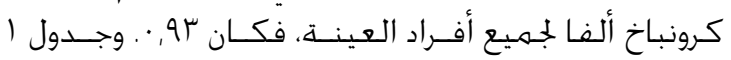

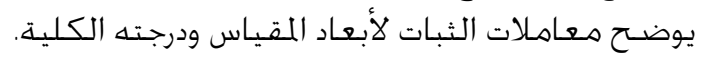

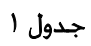
معاملات الثبات لمقياس المؤشرات النوعية

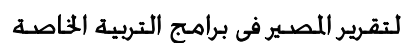
بطريقني: الإعادة والاتساق الداخلي لئي

\begin{tabular}{|c|c|c|c|}
\hline كَرونباخ & الاستقـرار & أبعاد المقياس & الرقم \\
\hline \multirow{3}{*}{$\cdot, V r$} & \multirow{3}{*}{$\cdot .91$} & البرنامج & \\
\hline & & التربوي & 1 \\
\hline & & الفـردي & \\
\hline \multirow[t]{2}{*}{$\cdot, V_{1}$} & \multirow[t]{2}{*}{$\cdot, 9 \varepsilon$} & التدريستريجيات & r \\
\hline & & خدمات & \\
\hline \multirow[t]{2}{*}{$\cdot, \wedge$} & \multirow[t]{2}{*}{$\cdot, 97$} & الطلبة & $r$ \\
\hline & & والنشـاطات & \\
\hline$\cdot, \wedge 1$ & $\cdot, 9 \mathrm{~V}$ & الأسـر & $\varepsilon$ \\
\hline$\cdot, \wedge 0$ & $\cdot, 9 \mathrm{~V}$ & العاملون & 0 \\
\hline \multirow[t]{2}{*}{$\cdot, v \varepsilon$} & \multirow[t]{2}{*}{$\cdot, 9 \wedge$} & البيئة المادية & 1 \\
\hline & & بيئة & \\
\hline \multirow[t]{2}{*}{$\cdot, \Lambda \Gamma$} & \multirow[t]{2}{*}{$\cdot, 97$} & المؤسـســة & v \\
\hline & & والجو العام & \\
\hline$\cdot, \wedge$ & $\cdot, 90$ & الذاتقيبم & $\wedge$ \\
\hline$\cdot, 9 \pi$ & $\cdot, 9 \mathrm{~V}$ & الكلية & 9 \\
\hline
\end{tabular}

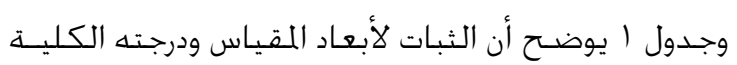
ملائم لأغراض الدراسـة.

إجراءات الدراسـة

لتحقيق هـدف الدراسـة الخـالية والإجابة عـن تســاؤلكها، تم

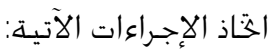




\begin{tabular}{|c|c|c|c|}
\hline المعيارية & 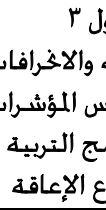 & 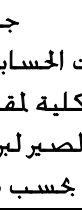 & 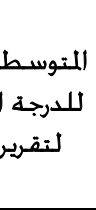 \\
\hline اللعياري المياف & المتوسـطـابي & الأفراد & الإعاقة \\
\hline 9 & 112 & 10 & سإعـاقـة \\
\hline 9 & 110 & 1. & بصـرية \\
\hline 11 & $1 \cdot V$ & 15 & إعـاقة \\
\hline 14 & $1 \cdot 0$ & 10 & عقلية إعاقة \\
\hline 15 & 1.9 & $\pi$ & الجمهـوع \\
\hline
\end{tabular}

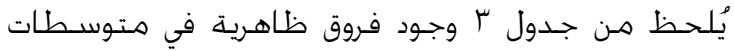

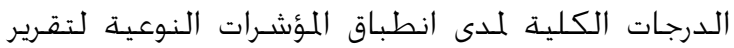

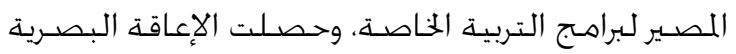

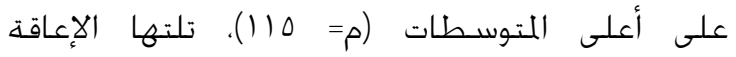

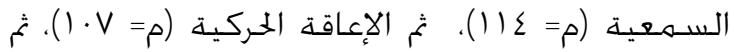

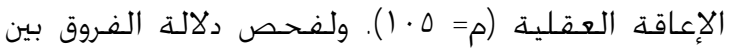

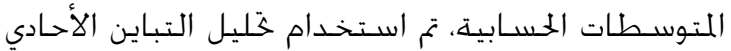
ANOVA

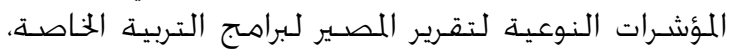
وجـدول ع يبين ذلك.

جدول

\begin{tabular}{|c|c|c|c|c|c|}
\hline الدلالة & فيمة ف & متوسعـات & درجات & مجربموعات & التباين \\
\hline$\cdot, \cdot \Gamma$ & $r$ & $\sum 0 T$ & $r$ & $1 r 01$ & الجمهوعات بين \\
\hline- & - & $1 \% \mathrm{~V}$ & $\Delta \Lambda$ & V97. & الجمهوعات \\
\hline - & - & - & 1) & QHIV & الكلي \\
\hline
\end{tabular}

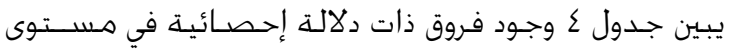

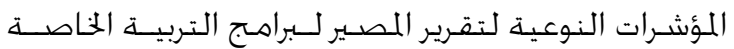

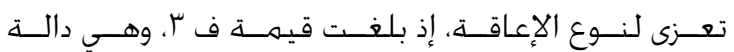

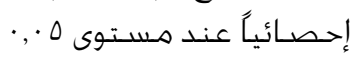

\section{مناقشــــ النتائج}

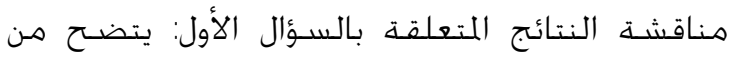

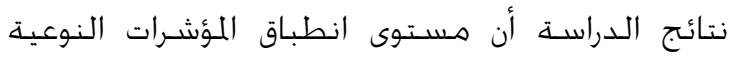

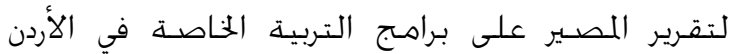

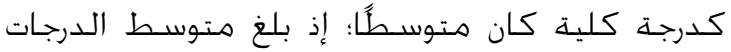

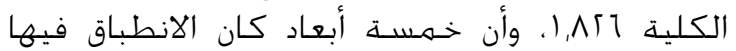

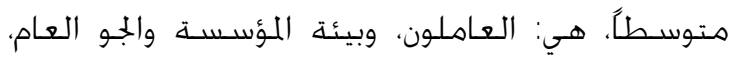

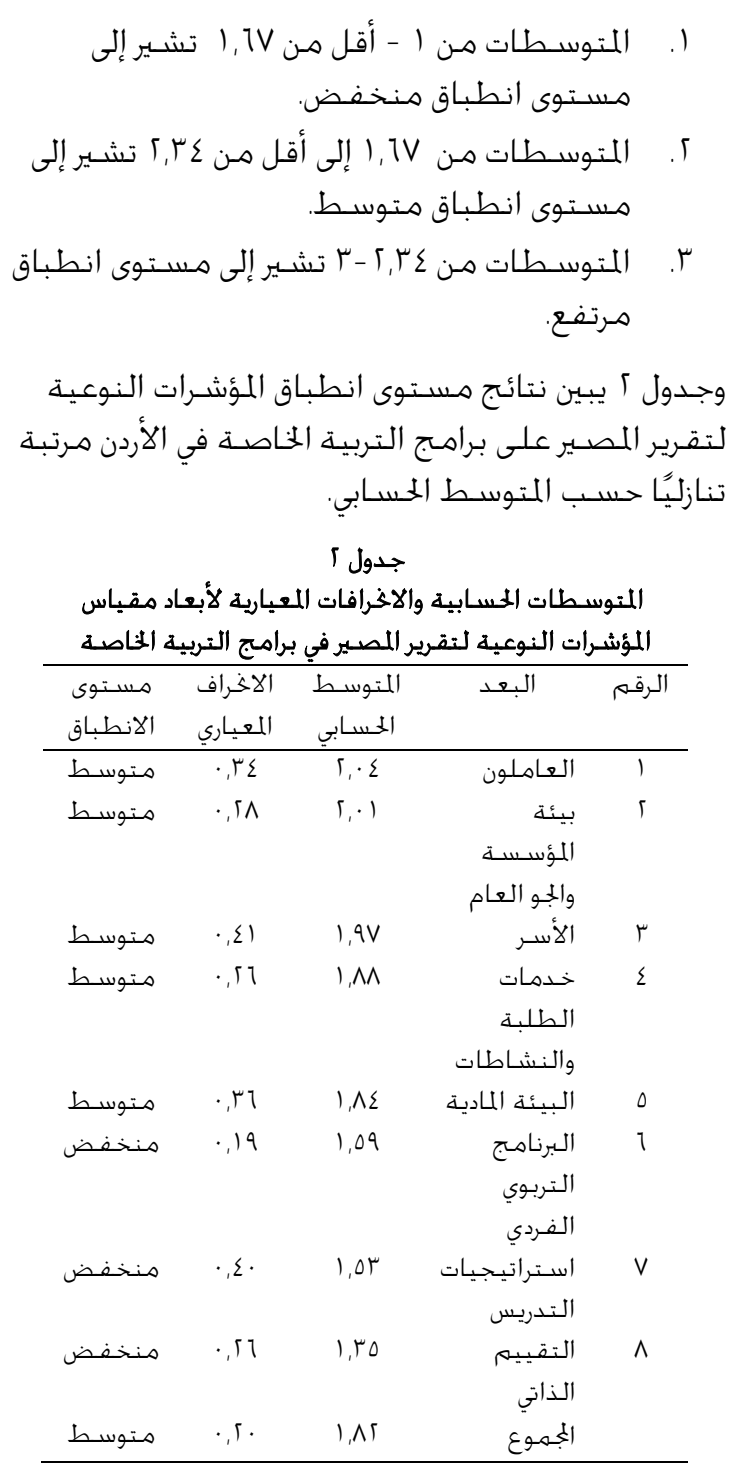

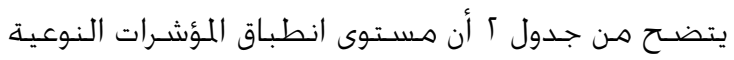

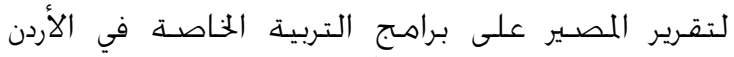

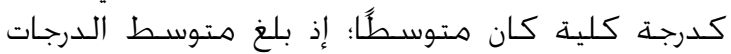

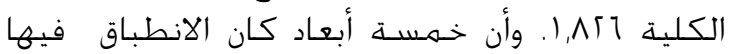

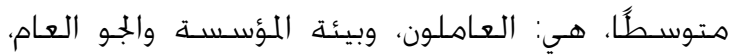

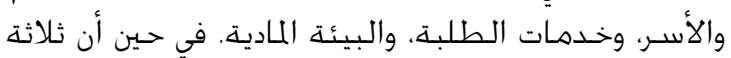

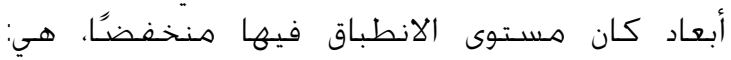

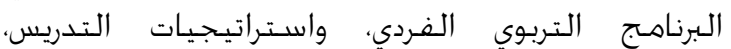
والتقييـم الذاتي. الإجابة عن السؤال الأول. وهو: هل هنالك فـروق دالة

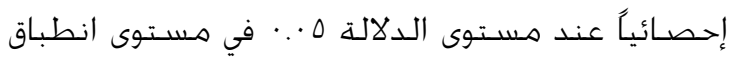

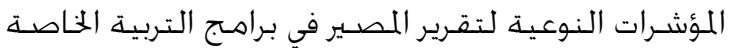

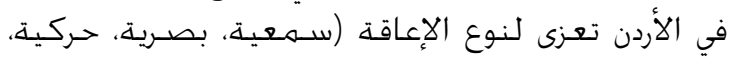

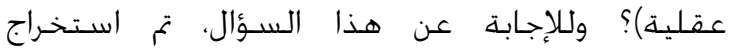

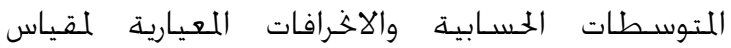
المؤشـرات النوعيـة لتقـرير المصـير في الدرجـة الكلية. وجـدول ب يوضسح ذلك. 


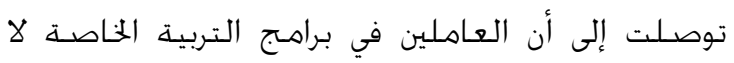

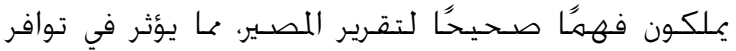

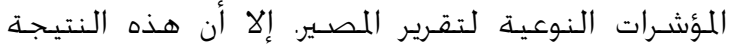

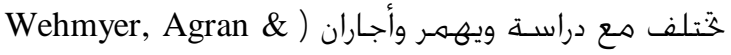

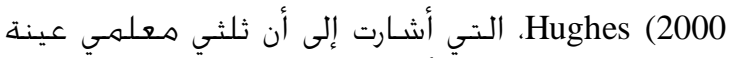

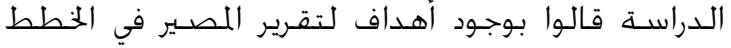
الفـردية.

يمكن تفسير اخففاض مستوى انطباق المؤشـرات النوعية

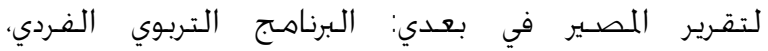

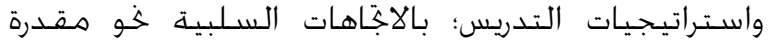

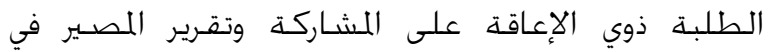

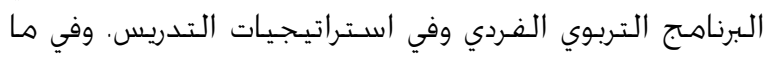

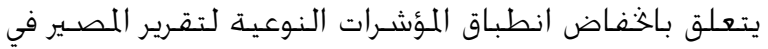

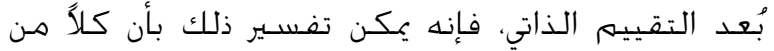

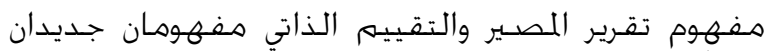

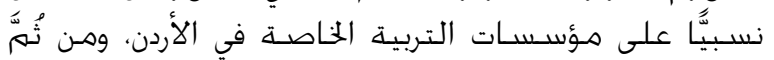
فإنه من المنطق أن يكون انطباق المؤشرات النوات النوعية

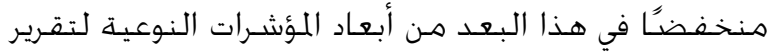
المسير في براهج التربية الخاصـة.

مناقشـة النتائج المتعلقة بالسؤال الثاني: تشـير نتائج

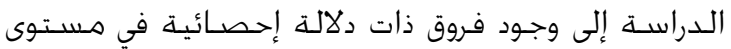

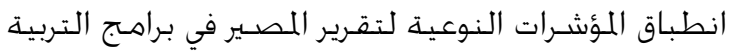

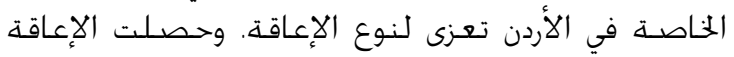
البصـرية على أعلى المتوسـطات، تلتها الإعاقة السـمعية.

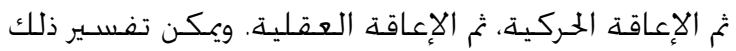

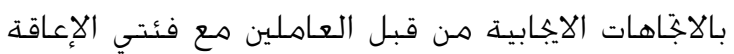

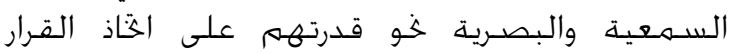

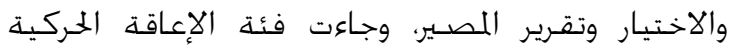

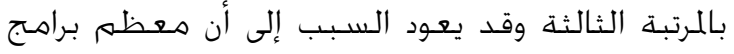

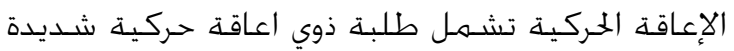

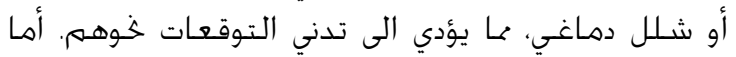

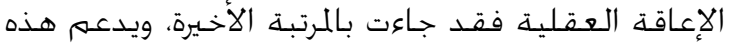

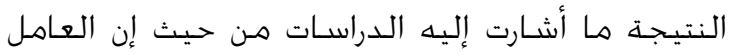

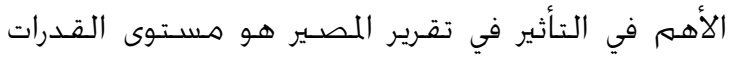
(Strnadova, and Evans, 2012; Stancliffe et العقلية فمدير al. ,2000; Wehmeyer ,1996; Wehmeyer \& Garner, (2003: وكون النسـاء ذوات الإعاقة: السـعـية، والبصـرية.

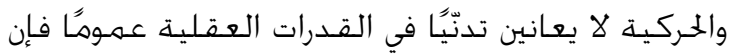
ذلك ينسجهم مع هذه النتيجة.

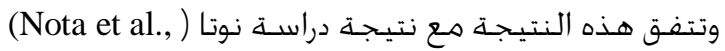

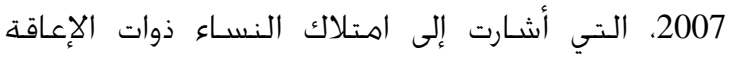

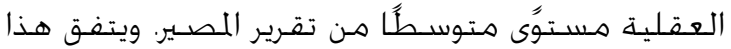

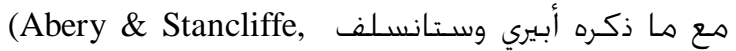

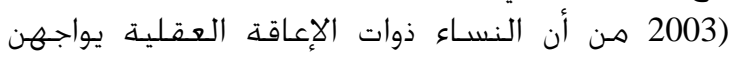
معيقات أكثر لتطوير تقرير المسير. كما تتفق هذه الإنه

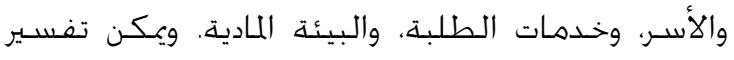

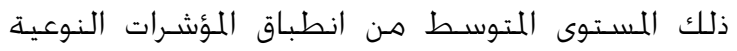

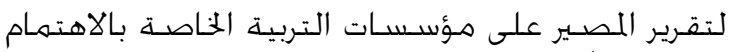

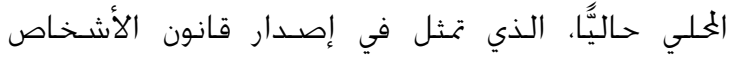

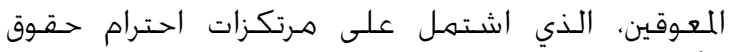

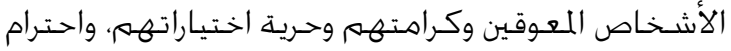

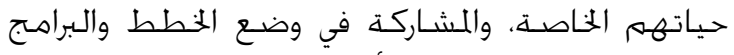

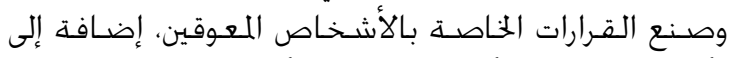

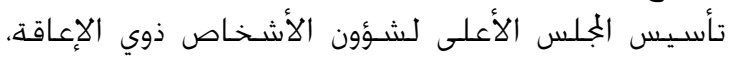

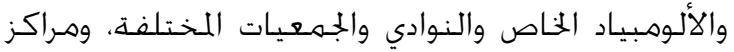

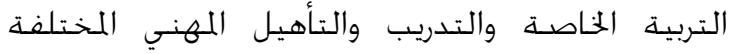

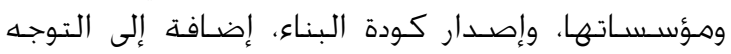

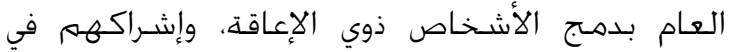

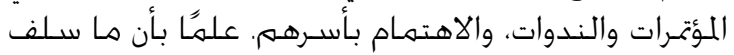

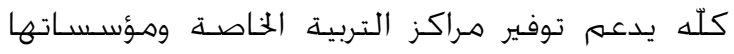

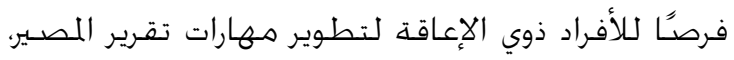

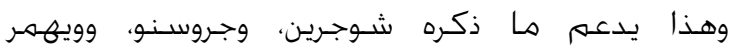
(Shogren et al., 2007; Crosnoe, 2004; Wehmeyer et al., 2003) وتوافر الفرص والخدمات.

كما أشارت نتائج الدراسـة الحالية إلى أن ثلاثة أبعاد كان

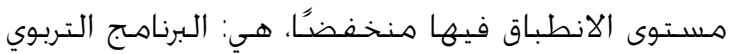

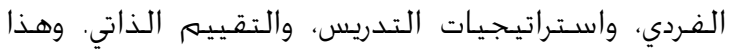

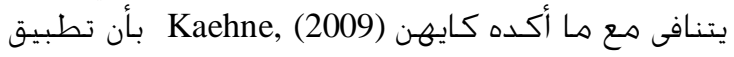

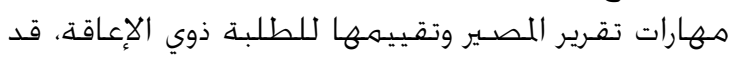

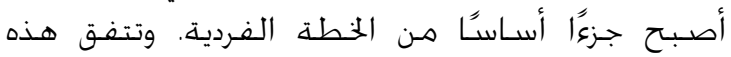

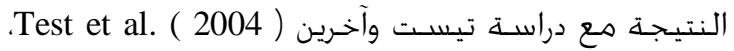

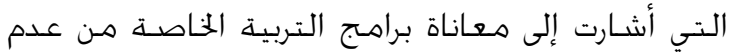

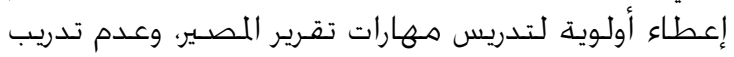

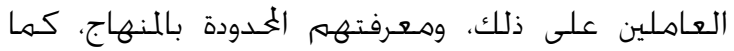

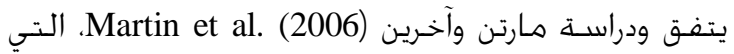

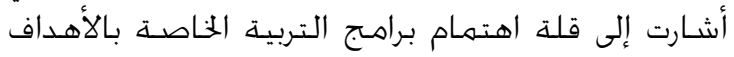

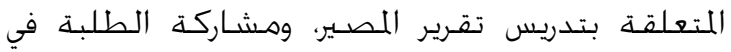

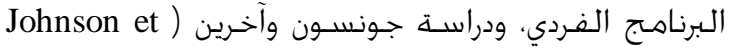

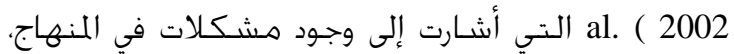

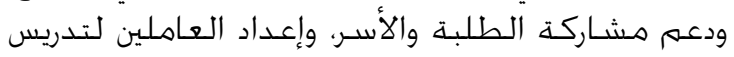

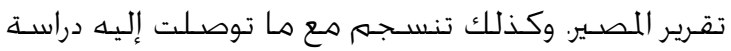

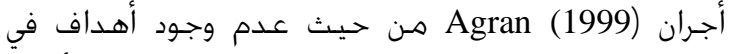
الخطة التربوية الفردية تتعلق بتقرير المصير. وتتفق أيضًا

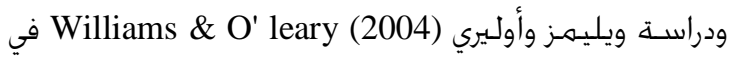
أن الطلبة لا يشتركوا بفعالية في عملية التخطيط.

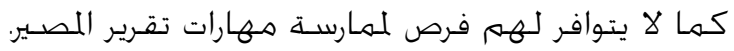

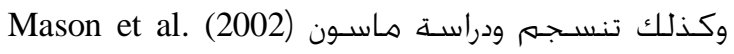
التي أشـارت إلى عدم إعداد الطلبة للمشاركة بفعالية

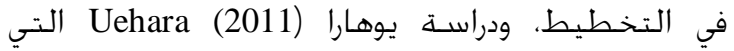




\section{المراجع}

\section{References}

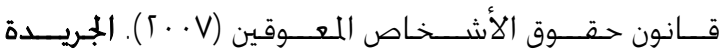

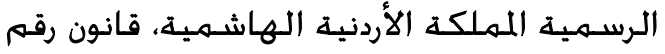

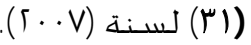

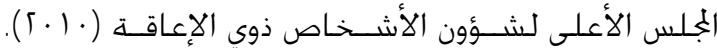

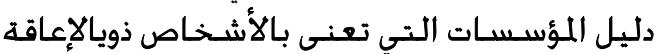

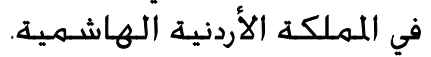

Abery, H., \& Stancliffe, J. (2003). An ecological theory of self-determination: theoretical foundation. In Wehmeyer M. L., A bery B. H., Mithauf D. E. \&Stancliffe R. J. (Eds.), Theory in self-determination: Foundation for educational practice, (pp. 25-42). Springfield, IL: Charles C. Thomas.

Ackerman, B. (2006). learning self-determination: lessons from the literature for work with children and youth with emotional and behavioral disabilities. Faculuty publications and presentation. Paper 6.

Agran, M., Snow, K., \& Swaner, J. (1999). Teacher perceptions of self-determination: Benefits, characteristics, strategies. Education and Training in $M$ ental Retardation and D evelopmental D isabilities, 34(3), 293-301.

AIR Self-Determination Scale and User Guide (1994). A merican Institutes for Research, Columbia U niversity

Carter, E., Lane, K., Pierson, M., \& Stang, K. (2008). Promoting self-determination for transitionage youth: Views of high school general and special educators. Exceptional Children, 75(4), 55-70.

Crosnoe, R. (2004). Social capital and the interplay of families and schools. Journal of $M$ arriage and Family, 66(3), 267-280.

Field, S., \& H offman A ,. (2002). Preparing youth to exercise self-determination Quality indicators of school environments that promote the acquisition of knowledge, skills, and beliefs related to self-determination. Journal of D isability Policy Studies, 13(2), 113-118.

Field, S., \& H offman, A. (1994). Development of a model for self-determination. Career Development for Exceptional Individuals, 17(3), 159-169.

Field, S., Sarver, M., \& Shaw, R (2003). Selfdetermination: a key to success in postsecondary education for students with
النتيجـة مع ما توصـلت له دراسـة ويهمـر وبالمر (Wehmyer \& Palmer, 2003)؛ حيث أشـارت إلى معاناة

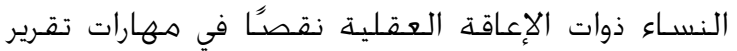

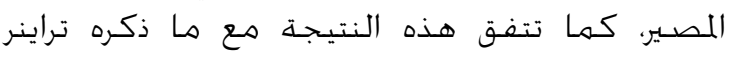

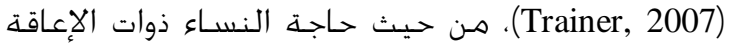
العقلية إلى تطوير مكوّنات تقرير المصـير الأسـاسـية،

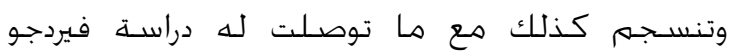
(Verdugo et al., 2011)

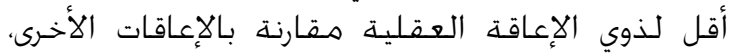

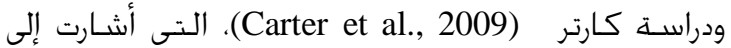

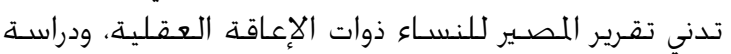

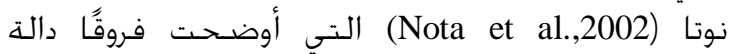

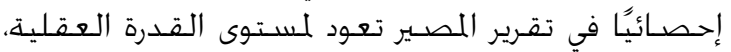

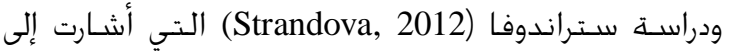

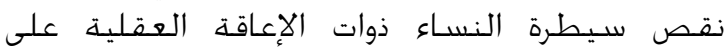
حياتهنّ؛ بسـبب الإعاقة العقلية. التوصيات

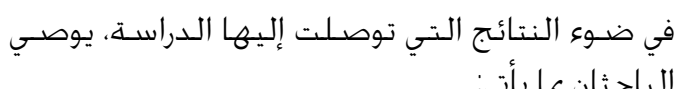
ضـرورة قيام المسؤولين عن الخدمات المتعلقـة

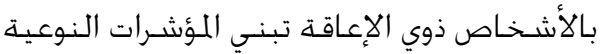

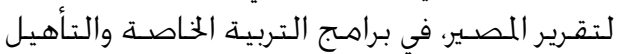
المهني.

العمـل على تكييف برامه إعـداد معلمي التربية

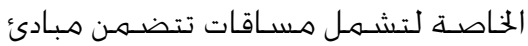

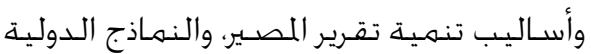
المتوافرة. توفير البراهـج التـدريبية في أثناء الخدمة للعلهي

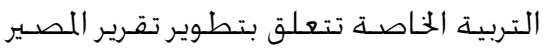
للأشخاص ذوي الإعاقة.

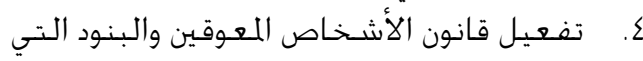

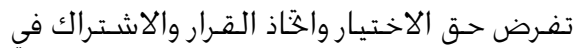

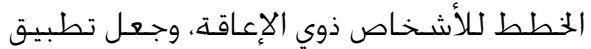

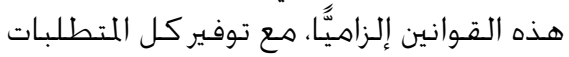
اللازهـة لتطبيقها.

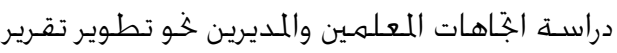
المصير عند الأشخاص ذوي الإعاقة.

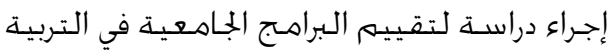

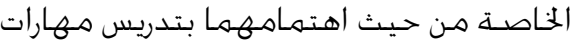

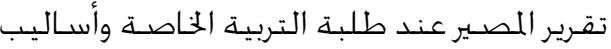
تطوير تقرير المصير عند الأشخاص التهربـ ذوي الإعاقة.

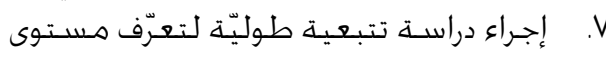

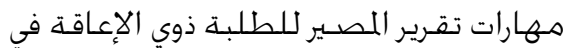

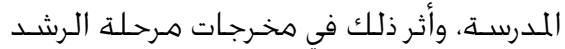
ونوعيـة الخياة. 
learning disabilities. Remedial and Special Education, 24 (6), 339-349.

Geenen, S., Powers, L., Hogansen, M., \& Pittman, J. (2007). Youth with disabilities in foster care: Developing self-determination within a context of struggle and disempowerment. Exceptionality, 15(1), 17-30.

Gills, L., \& Tonya, L. (2011). Kujichagalia! selfdetermination in young africanamerican women with disabilities during the transition process (Unpublished Doctoral Dissertation). University of South A frica.

Johnson, R., Stodden, A., Emanuel, J., Luecking, R., \& Mack, M. (2002). Current challenges facing secondary education and transition services: What research tells us. Exceptional Children, 68(4), 519-531.

Kaehne, A. (2009). Choice for young people with learning disabilities in post-education transition. M ental health review journal. 14 (2), 115-128.

Kipp, L., \& Amorose A. (2005). Perceived motivational climate and self-determination motivation in female high school. Athlete Journal of Sport Behavior, 31 (2), 108-130.

Lee, S., \& Wehmeyer, L. (2004). A review of the Korean literature related to self-determination: Future directions and practices for promoting the self-determination of students with disabilities. Korean Journal of Special Education, 38(4), 369-390.

Lee, S., Palmer, S., Turnbull, A., \& Wehmeyer, M. (2006). A model for parent - teacher collaboration to promote self-determination in young children with disability. Teaching Exceptional Children. 38 (3). 225-237.

Martin, E., Van Dycke, L., Greene, A., Gardner, E., \& Lovett, L. (2006). Increasing student participation in IEP meetings: Establishing the self-directed IEP as an evidenced-based practice. Exceptional Children, 72(3), 299-316.

Mason, Y., McGahee-Kovac, M., Johnson, L., \& Stillerman, S. (2002). Implementing student-led IEPS: Student participation and student and teacher reactions. Career Development for Exceptional Individuals, 25(2), 171-191.

Mithaug, E. (1993). Self-regulation theory: how optimal adjustment maximizes gain. Westport: CT. Praeger Publishers.

Muller, F., \& Louw, J. (2004). Learning Environment, motivation and interest: Perspectives on self-determination theory. South A frica journal of Psychology, 34(2),169-190.

O'Brien, D., Revell, G., \& West, M. (2003). The impact of the current employment policy environment on self-determination of individuals with disabilities. Journal of V ocational Rehabilitation, 19(2), 105-118.

Powers, J. (2010). understanding the development of self-determination in youth with disabilities in foster care. Ph. D thesis, Portland state university.

Rayn, M., \& Deci, L. (2000). Self-determination theory and the facilitation of intrinsic motivation, social development, and wellbeing. A merican Psychologist, 55(1), 68-78.

Rubin, S. \& Roessler, R. (1995). Foundation of the vocational rehabilitation process. Texas: Pored, Shoal Creek Boulevard Austin.

Sarver, D. (2000). A study of relationship between personal and environmental factors bearing on selfdetermination and academic success of university students with learning disabilities (Unpublished Doctoral Dissertation). University of Florida, Gainesville.

Shogren, A., Wehmeyer, L., Palmer, B., Soukup, H., Little, D., Garner, N., \& Lawrence, M. (2007). Examining individual and ecological predictors of the self-determination of students with disabilities. Exceptional Children, 73(4), 488-509.

Sprague, J., \& H ayes J. (2000). Self-determination and empowerment: A feminist standpoint analysis of talk about disability. A merican Journal of Community Psychology, 28 (5), 109122.

Strnadova, I., \& Evans, D. (2012). Subjective quality of life of women with intellectual disabilities: the role of perceived control over their own life in self-determined behavior. Journal of A pplied Research in Intellectual D isabilities, 25 (3), 71-79.

Taylor, R., Richards, S., \& Brady, M. (2005). M ental retardation: historical perspectives, current practices and future directions. Boston: Allyn \& Bacon.

Test, W., Mason, C., Hughes, C., Konrad, M., Neale, M., \& Wood, M. (2004). Student involvement in individualized education program meetings. Exceptional Children, 70(4), 391-412.

Thoma, C., \& Sax, C. (2003). Self-determination: What do rehabilitation counseling students know and where do they learn it?. Journal of vocational Rehabilitation, 19 (2), 89-94.

Trainor A. (2007). Perceptions of adolescent girls with LD regarding self-determination and postsecondary transition planning. Learning D isabilities Q uarterly Journal. 30(2). 31-45.

Trainor, A. (2002). Self-determination for students with learning disabilities: Is it a universal 
value? International Journal of $\mathrm{Q}$ ualitative Studies in Education, 15 (3), 711-725.

Turnbull, P., \& Turnbull, R. (2001). Families, professionals, and exceptionality: Collaborating for empowerment(4th Ed.). Upper Saddle River. NJ: Merrill/ Prentice Hail.

Uehara, L., \& Tua-Tupuola, A. (2011). Navigating the cultural landscape towards selfdetermination: Results of an exploratory study in A merican Samoa. Review of D isability Studies, 9(2), 5-21.

US Department of Health and Human Services, Administration on Developmental Disabilities A National Gateway to Self-Determination (2011). A Series of Papers on Scaling-U p Efforts to Promote Self-D etermination. Paper 2: Personal SD and $M$ oderating Variables that Impact Efforts to Promote SD.

Verdugo, R., Martín-Ingelmo, B., Jordán de Urríes, C., \& Sánchez M. C. (2011). Impact on quality of life and self-determination of a national program for increasing supported employment in Europe. Journal of Vocational Rehabilitation. 31(2), 55-64.

Wehmeyer L., Palmer B., Soukup H., Garner W., \& Lawrence M (2007). Self-determination and student transition planning knowledge and skills: Predicting involvement. Exceptionality,15(1), 31-44

Wehmeyer, L., \& Palmer, B. (2003). Adult outcomes for students with cognitive disabilities three years after high school: The impact of selfdetermination. Education and Training in D evelopmental D isabilities, 38(3),131-144.

Wehmeyer, L., Agran, M., \& Hughes, C. (2000). A national survey of teachers' promotion of selfdetermination and student-directed learning. Journal of Special Education, 34(3), 58-68.

Wehmeyer, M., \& Schwartz, M. (1997). Selfdetermination and positive adult outcomes: $A$ follow-up study of youth with mental retardation or learning disabilities. Exceptional Children, 63(2), 245-255.

Wehmeyer, M., Agran, M., Hughes, C., Martin, J., Mithaug, D., \& Palmer, S. (2007). Promoting self-determination in students with developmental disabilities. New York: The Guilford Press.

Wehmeyer, M., Field, S., Doren, B., Jones, B., \& Mason, C. (2004). Self-determination and student involvement in standards-based reform. Exceptional Children, 70, 413-425

Williams, M., \& O'Leary, E. (2004). What we've learned and where we go from here. Career Development for Exceptional Individuals, 24(4), 51-71. 